\title{
Norrish' type I and II reactions and their role in the building of photochemical science
}

\author{
Angelo Albini ${ }^{1}$ (1)
}

Received: 12 October 2020 / Accepted: 25 November 2020 / Published online: 2 January 2021

(c) European Photochemistry Association,European Society for Photobiology 2021

\begin{abstract}
The highly inspiring work by Professor Norrish has exerted a consistent influence on chemistry and, in particular, on photochemistry, where he was one of the first scientists, along with Gilbert N. Lewis, able to develop a viable concept of excited states and their rate of reaction. However, having him listed among the authors of two name reactions, known as Norrish Type I and Type II, plus a subcase of the latter that is the Yang cyclization, is not coherent. Indeed, Norrish had no interest in organic synthesis, while this is a required feature of name reactions. And, at any rate, Professors Ciamician and Paternò had arrived at the same conclusions with the same compounds much earlier, except for the measurement of quantum yields. Things are too long away now for introducing any change, but one should remember that using Norrish name here is a mistake, while it would be appropriate to add the name of Ciamician for a different name reaction, the $2+2$ cycloaddition of alkenes and conjugated carbonyls. In 1968, such an attribution was proposed by Professor Schömberg, but this had no effect and the present assignment has become a habit. The most important thing, however, is that the $2+2$ reaction has become one of the most popular reactions in synthetic photochemistry.
\end{abstract}

\section{Introduction: name reactions}

The lemma name reaction bears a twofold meaning in organic chemistry. On one hand, it is added to honor the name of a chemistry practitioner that has been able to invent a novel reaction, on another one it works as a type of shorthand that avoids the need to give a lengthier explanation of the features of a particular transformation of interest [1-5]. Mentioning a name reaction allows a knowledgeable listener to bring to mind the possible substrates, reaction conditions, and mechanistic details, and thus are used when considering large scope chemical steps as well as their limitations in retrosynthetic schemes.

Among photochemical reactions universally designed as name reaction, the Norrish Type I and Type II photoreactions of aldehydes, ketones and aromatic nitro compounds have a paramount role $[6,7]$. However, applying this label

Dedicated with thanks to Professors M. Fagnoni, M. Mella, S. Protti, D. Ravelli, D. Dondi, with whom had the pleasure to collaborate, on the occasion of my retirement.

Angelo Albini

angelo.albini@unipv.it

1 University of Pavia, Pavia, Italy does not seem appropriate in this case, since Norrish was not interested in synthesis, but rather in high energy reactions such as vapor phase reactions, the kinetics of combustion and explosions and the intermediates formed under such conditions (determined by flash photolysis), the actual topic for which he was awarded the Nobel Prize in 1967 [8].

For reasons that will be specified in the following, it may be of some interest to retrace the early history of these reactions. Chemistry is a large scope and perfectly univocal science, but it answers different questions in its different parts. Each scientist, as well as every human, may prefer different rationalizations, obviously, and thus using different methods. Staying among the sayings of the 'Fathers of photochemistry', as an example, one finds that Norrish had declared that 'he had been puzzled that organic chemists were primitive in their methods ... they got a strong lamp, stuck it in the middle of the reaction and waited for something to happen' [9]. It is not surprising that Norrish considered it disagreeable to explore reactions under such poorly defined conditions, as his own research was characterized by carefully described experimental conditions. A thoroughly designed set of conditions was required to test as richly as possible theory and the interplay of theory and experimental studies have been peculiarly fruitful in this topic [10]. On the other hand, Paternò thought that even Ciamician had no sufficient 
Scheme 1 Main photoprocesses of ketones a $\alpha$-cleavage, Norrish Type I with possible recombination a' measured by racemization, $\mathbf{b} \gamma$-hydrogen transfer followed either by b' Norrish Type II fragmentation, or by b" $\beta, \gamma$-cleavage, Yang cyclization, or finally $\mathbf{c}$ hydrogen acceptance and $\mathbf{c}$ ' addition reaction

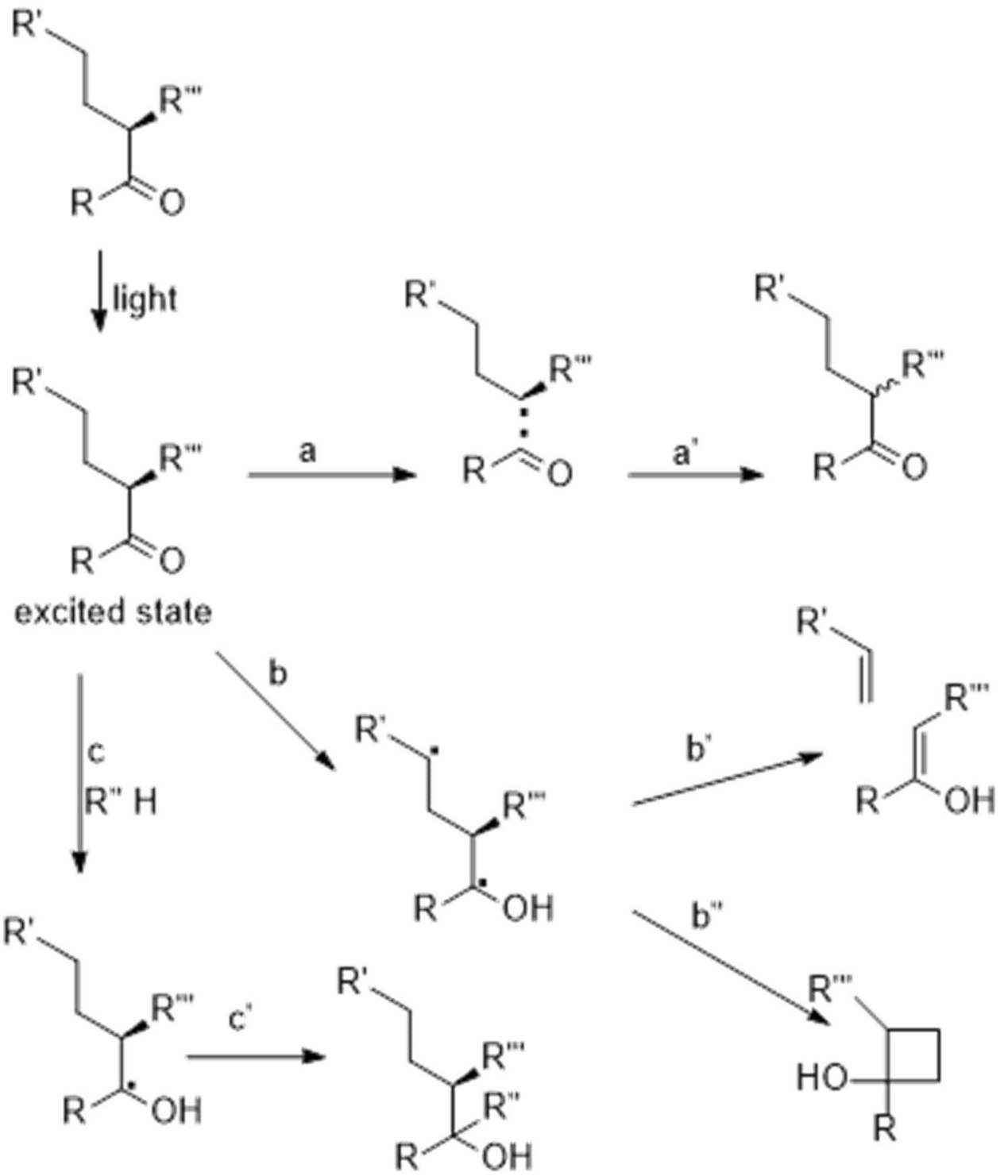

inspiration for organic synthesis [11], while MIT Professor Georg Büchi found that photochemistry was not reliable enough, e. g. in Paternò's synthesis of oxetanes, thus depriving researchers of the pleasure of building and verifying a retrosynthetic scheme [12]. The key photochemical reactions that now go under the name of Norrish types are summarized in Scheme 1.

Would Professor Norrish have any interest in syntetic chemistry, he would have checked the literature on this topic in detail. Actually, he never quoted the papers published over 30 years before by Ciamician and Paternò [13]. Actually, he acted contrary to what MIT professor Georg Büchi did in a quite similar case with another important paper of 4 decades earlier, when he fished in the literature of Paternò's syntheses of oxetanes and repeated (and confirmed) some of the experiments. It is undoubtedly correct that both names are used when alluding to the photochemical
$2+2$ cycloaddition of ketones and alkenes to form oxetanes. From the beginning, Paternò confronted the new reaction as would a synthesis practitioner; first, he reduced the reaction to the simplest possible form, formaldehyde + ethylene and, second, he looked for the scope, thus evidencing e.g. that a phenol moiety prevented the reaction, while a methoxyphenyl did not [14]. Scheme 1 gathers the main photoreactions of carbonyl derivatives (see Scheme 1).

The historic development of the Norrish reactions is demonstrated in Scheme 2, where the number of papers indicating in the title the name "Norrish" published in that year is plotted vs the year. This highlights another aspect of these reactions, the fact that a sharp increase in photochemical literature took place only after 1965 and followed a strictly analogous behavior with photochemistry in general [15]. Clearly, irradiation brought cause reactions different from those of thermal chemistry, although chemists were able to 
Scheme 2 Photochemical reactions of aromatic carbonyls

$$
\mathrm{Ph}_{2} \mathrm{CO}+\mathrm{PhMe} \stackrel{\text { light }}{\longrightarrow}+\mathrm{PhEt} \stackrel{\text { light }}{\longrightarrow}
$$

${ }_{\mathrm{Ph}}^{\mathrm{Ph}} \overbrace{\mathrm{Ph}}^{\mathrm{OH}}$ rationalize them through the same general effects. It was reserved for superior minds to recognize their result with no advanced separation and purification treatment method available. When such methods became available in the 'golden age of photochemistry and a better instrumentation was created within a short period of time, thus achieving the conditions of accumulating many photo products with a well-established structure, a thing that was virtually.

impossible to reach in an earlier time. The case of ketones was fortunate because of the related structure of the radical cation and of the excited state that resulted in related information from mass spectroscopy and from irradiation (compare the McLafferty rearrangement [16], which offered both a mechanistic rationalization and a peculiar signature.

The two Italian teams attempted to clarify which may be the mechanism involved in the reactions they were studying, although no description of electronically excited states was available at the moment (and their laboratories would be the right place where to look for since both of them followed attentively the development of molecular physics). These included a number of reactions of aldehydes, ketones and nitroaromatic derivatives. In retrospect, their work is highly prophetic, since what they found were processes that had no precedent and every part of their papers is an intellectual pleasure, due to the superb exploitation of every piece of knowledge in contemporary science to arrive in the correct structure assignment, and also the pleasure of creating new beautiful molecules. Everyone that has worked in a laboratory can't help in participating in Paternò's pleasure when he defines 'magnificent' the crystals of one of the hydrocarbons formed in one of his reactions. Such reactions 'caused by light' are nowadays well described in text books and considered an excellent example of photoreactions via diradicals or a couple of radicals (see Scheme 1, path a). Even if in several cases it was possible to recognize the primary products, it is apparent that the mechanism was not the primary topic of the studies.
The possibility to direct the photoreaction toward different targets is a big synthetic atout. The different approach is apparent when comparing the different secondary evolution of the intermediates. As an example, the Norrish II elimination reaction may be compared with the Yang cyclization, both of which result from the initial $\delta-H$ transfer (paths $b$, b', vs b, b' ' in Scheme 1) and the actual course of the process can be directed, at least to some degree, by choosing the appropriate conditions, in particular, by carrying out the irradiations in the crystal state [17] or on a milky nanocrystalline suspension [18] (Fig. 1).

The sharp increase of papers from 1965 on follows the general behavior of organic photochemistry in those years, and parallels the development of modern methods for separating compounds and recognizing their structure [15] that

\section{Norrish 1}

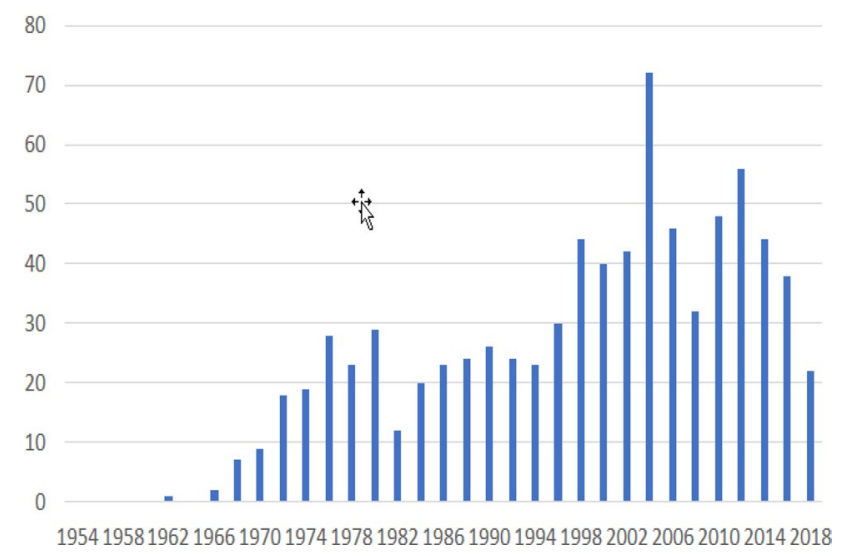

Fig. 1 Yearly distribution of papers indicating in the title the name Norrish. The sharp increase of papers from 1965 on follows the general behavior of organic photochemistry in those years and parallels the development of modern methods for separating compounds and recognizing their structure 
Scheme 3 Bimolecular reactions of carbonyl derivatives

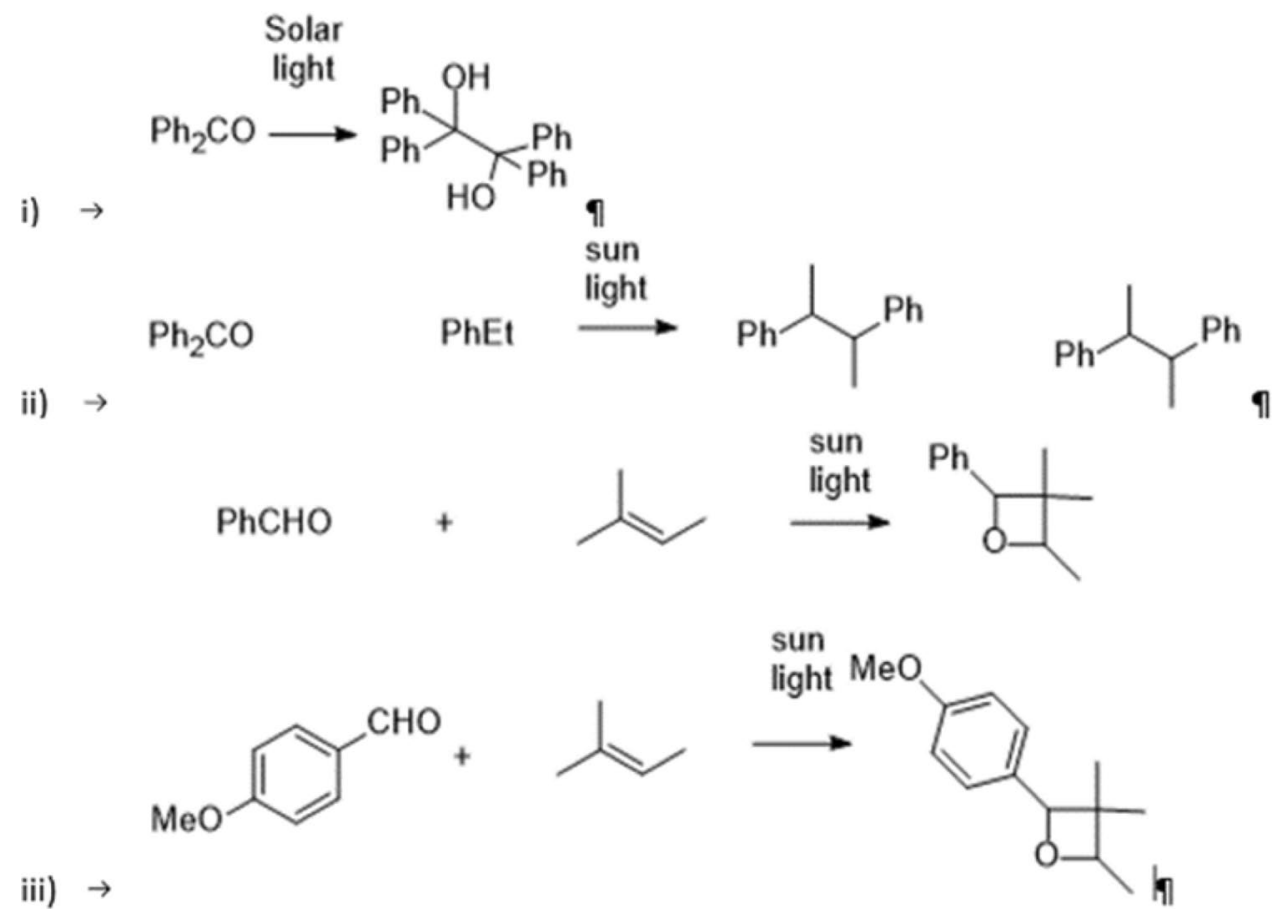

was vital to photochemistry, where peculiar reactions had to be rationalized.

\section{Ciamician and Paternò contribution}

Two authoritative contributions on the topic photochemistry came in the early years of the XIX Century from two Italian chemists: Gacomo Luigi Ciamician (1857-1922) that was born to the Armenian community in Trieste and did postdoctoral work in Cannizzaro's laboratory in Rome, then took a call for a chair in Padova but transferred after a few months to Bologna, where was followed by Silber [20]. Emanuele Paternò, Marquess of Sessa (1847-1935), succeeded his mentor, Stanislao Cannizzaro, as Professor of Chemistry in Rome from 1892.

All of the reactions shown in Scheme 1 were first reported by either Ciamician or Paternò or by both of them that, despite the poor instrumentation they could use at the beginning of the XIX century, were able to assign the correct sequence operating. Ciamician published a range of $\alpha$-cleavage reactions from open-chain (acetone, 2-hexanone, and dibenzyl ketone, see examples in Scheme 3), cyclic (cyclohexanone and its methyl derivatives, menthone) and bicyclic ketones (camphor, fenchone), besides a large number of oxidative cleavage reactions. He also found that a general course of the reaction, that conformed to the scheme above, with a preference for splitting off the most heavily substituted carbon, when two ways were possible, and occurring with a rearrangement when a 'normal' course was precluded. The monomolecular reacting ketones studied could be grouped in two classes, the short aliphatic ketones that mainly underwent an $\alpha$-cleavage and the longchain $(C \geq 4)$ aliphatic ketones that mainly underwent $\beta, \gamma$ cleavage to yield a methyl ketone and an alkene. Aromatic ketones reacted mainly intermolecularly, to give oxidative dimerization, or, in the presence of alkenes, to give oxetanes. $\gamma$-Hydrogen transfer was an alternative path for intramolecular hydrogen transfer from such a spatially convenient position, but otherwise also from a chemically activated position. It is not easy to distinguish exactly which reaction was first uncovered in Bologna or in Rome and as matter of fact there was some polemic between the two laboratories [21, 22].

Ciamician got first interested in photochemistry when still in Rome in 1886 , but as was customary at the time, he did not hasten to publish the results, once his interest in the matter had been made known (furthermore, he was quite busy with other research topics, viz. the isolation and structure assignment of natural products as well as the study of the chemistry of pyrrole and phenol, for which in fact he is best known even today 2). His papers on photochemistry started to appear continuously since 1900 in major journals, mainly the Berichte. [13] At this point not only the results of many experiments had become available, but also the main tenets about photochemistry as he conceived it had been formulated for a good part and he was able to present a first overview of his work in 1902 (in Italian, in Rome) [23]. He made no hasty move, however, and still in 1904, when choosing a topic for a talk before the German Chemical Society in Berlin, judged not yet mature his work in this 
field and rather chose to present his previous work on heterocycles (see below) [24] $]^{1}$

At that time, the action of light on matter was known, but mainly for photography or for explaining the degradation of dyes in textiles. As an example, a review published by Friedberg in 1899 under the title 'On recent process in photochemistry' is in fact an account of the latest development in photography [25]. Thus, the series of 33 photochemical papers published by Ciamician and his associate Silber between 1900 and 1915 under the title 'Chemical Action of Light' were an actual breakthrough and gave the most important contribution by a single group to the discovery of new photochemical reactions at that time and for many years to come [4]. Paternò was second only to them with the 12 papers of the series 'Synthesis by light' and, similarly, published a few exemplificative data, but then in a single output, with all of the results he had obtained in this field together with his decision to leave it. ${ }^{2}$

The debut of synthetic photochemistry on the international scene was marked by a talk in Paris in 1908, where Ciamician summarized and explained his results. Even nowadays it is worthwhile to go through the account of his discoveries as reported in the 1908 talk [26], where one can appreciate the large number of photochemical reactions that had been characterized by Ciamician in collaboration with Paul Silber and with a few other coworkers, as well as the attitude that had guided this long effort. The great vision of photochemistry as a 'better' chemistry, inspired by the mild conditions under which they occurred in green plants, had to be built on the basis of the patient isolation (with the then available techniques!) and structure attribution (often really unexpected at the time) to the products formed [27]. The sun irradiation intensity ensured that it could be exploited for affording energy sufficient to meet the needs of modern society was later documented in a talk by Ciamician in New York in 1912 [28], as well as by one by Paternò in Rome in 1906 [29].

Even more important in retrospect is the motivation Ciamician felt for this study, as clearly expressed in the Paris talk. The first words of his were: 'To the great successes of modern organic chemistry, in which French chemists had such an important role, it has been often reproached for having been reached with too big a show of strength. And, to be correct, one has to acknowledge that such objection is not groundless. The use of an aggressive reagent and a high temperature cannot be avoided when making organic

\footnotetext{
1 With the Great War and the death of Ciamician and the leaving of the field by Paternò, the Italian contribution to photochemistry decreased, although it was pursued, mainly by former pupils of Ciamician or Paternò.

2 There is a Ciamician reaction among name reactions, the Ciamician-Dennstedt ring expansion of pyrrole to pyridines [24].
}

synthesis in the laboratory. Per se, the strong energy would not be humiliating for modern organic chemistry, were it not that the organic world, in particular green plants, give the wonderful example of great results obtained, at least from what it seems, by using the least means.' Thus, he thought that photochemistry, besides enzymes, was the form of energy that nature used and made possible the occurrence of such complex reactions, and man now could, and actually must learn such methods. 'Besides enzymes, there is another agent that is all important, at least for green plants, and the influence of which on organic processes deserves an in-depth examination, and this is light [27]. The intervention of chlorophyll allows plants to store solar energy and transform it into chemical energy. It may thus happen that exploiting solar energy in the form of formaldehyde and its polymers, the carbohydrates, may become interesting also in a different way: when all of the coal will have been burned in our prodigal industries, it may be necessary, also for the economy of the society, to exploit solar energy. Photochemistry studies the conversion of the energy of radiation into chemical energy and chemical phenomena related to such problems.

This noble aim that was fully shared with Paternò, who expressed this idea by stating that chemistry had finally proved that synthetic compounds had no difference, in their structure and biological behavior, with the natural ones, and mankind now had to shift its aim from making useful compounds to how to produce them, in the best, mild and non-toxic way [27].

The general reactions uncovered by the two scientists are gathered in Scheme $2[30,31]$ and the following ones. Ciamician reports his research in the way synthesis practitioners are used to, by connecting previously revealed and present synthetic findings, as an example reaction discovered with cyclic and open-chain ketones [30]. Likewise, Paternò notes that these reactions involve the key step in organic synthesis, the formation of the most characteristic and relevant bond, the carbon-carbon bond [31].

There are three general reactions, for which Paternò claims priority, that is (i) the bimolecular reduction of ketones, (ii) the 'enolic' reactions involving hydrocarbons that contain an 'activated' $\mathrm{CH}_{2}$ group and participate in a kind of an aldol condensation, targeted the enolic reaction, and (iii) the $2+2$ cycloaddition of aldehydes and keto4nes and alkenes (Schemes 3,4) [31, 32].

The reaction indicated as (ii) was, the Authors noted, a synthetic equivalent of the aldol reaction, and correspondingly was labelled with the enolic reaction, but did not require any base. Several examples are quoted in a review on Paternò's own research, in which he also indicated some topics for future work. The following conclusions related to the phenomena observed in general are stated in the following ways. (1) The study of numerous synthetic 
Scheme 4 Further examples of bimolecular reactions from carbonyl derivatives

\section{$\mathrm{Ph}(\mathrm{Me}) \mathrm{COPh}$}<smiles>[R]c1ccc(C=O)cc1</smiles>

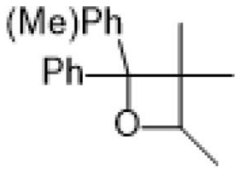

$2+2$

cycloaddition

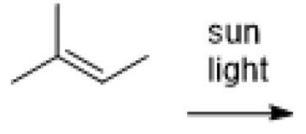

\section{$\mathrm{R}=\mathrm{H}, \mathrm{Me}, \mathrm{OMe}$}

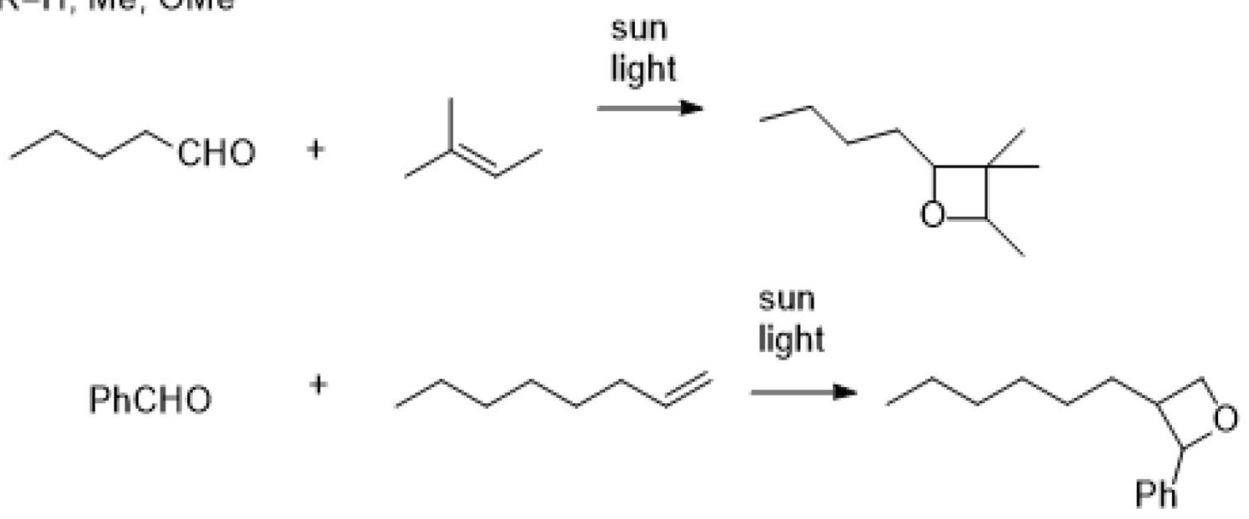

resins that were obtained gives grounds for an experience that will also help in clarifying the formation and the constitution of such natural resins. (2) The isolation of a colloidal substance with highly characteristic properties from sparteine and from strychnine in the forerunner of important investigations. (3) The transformation of pyrone into carbohydrates such as pentosans merit an in-depth study. (4) The formation of organic nitrogen compounds in an indefinite amount by the reduction of nitrates in the light of the presence of organic substances may become a fruitful field of research. (5) The synthesis of photoacetophenine and its analogs, when better understood, will be capable of much further development. (6) The possibility of introducing vegetable alkaloids of great physiological activity to complex lateral chains may greatly affect pharmacological studies. On the other hand, Paternò preferred not to pursue this research in person and announced that he would not continue these studies except incidentally [33].

In a similar way, Ciamician manifests himself to be interested in synthesis from the first line of his paper on photohydrolysis 'we anticipated that this holds not only for open-chain ketones but also for cyclic ketones'. Remarkably, Ciamician often uses the verb of his coinage, 'insolare' for exposing a solution to the sun, and he uses an amount of $100 \mathrm{~g}$ or at any rate more than $10 \mathrm{~g}$ for an irradiation of several months. Before exposing to the light the large flask (2.5 1 capacity) was flushed with either oxygen or an inert gas and flame-welded [34].
The structure attribution was based only on chemical reactions of the photoproducts and besides those indicated above, included some quite interesting monomolecular reactions (Scheme 5) [35-38].

These were the hydrolysis of ketones (as in the formation of $\omega$-hexenoic aldehyde from cyclohexanone by a cleavage or, in the presence of oxygen, of the corresponding acid). These was a general reaction, observed from the short $(\leq \mathrm{C} 3 \mathrm{H} 7)$ open-chain ketones, and medium cyclic aliphatic ( $>$ 4-membered) and bicyclic ketones (Scheme 6).

Some exceptions were carvone and fenchone that rather underwent a rearrangement before arriving at the end products. The intramolecular formation of a cyclobutane ring in the case of carvone was presented in a somewhat dubitative form by Ciamician and proved to be correct 45 years later again by Büchi (Schemes 7, 10) [37, 39, 40]. This fact, however, was not used for applying a twofold label of a name reaction, presumably because this was not originally planned as a single step. This important recognition was made by A Schőnberg, who in his classification of photochemical reactions the intramolecular $2+2$ cycloadditon for that this was a unique phenomenon and he proposed to Christianize it as the 'Ciamician's reaction' [41].

As for the mechanisms, that the beginning of the XIX century there was no general idea about the structure and role of radicals, nor indeed of the electronic structure of bonds in molecules, even if both Paternò and Ciamician were quite attentive to the advancements of physics. As an 
Scheme 5 Bimolecular reactions of carbonyl derivatives

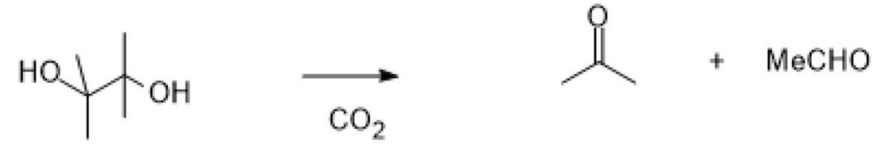

$\mathrm{Ph}_{2} \mathrm{CO}$

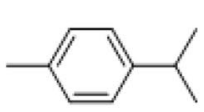

$\mathrm{Ph}_{2} \mathrm{CO}$

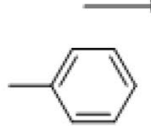

$\mathrm{Me}_{2} \mathrm{CO}$

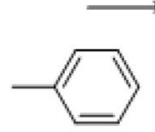<smiles>OC(c1ccccc1)(c1ccccc1)C(O)(c1ccccc1)c1ccccc1</smiles><smiles>Cc1ccc(C(C)(C)C(C)(C)c2ccc(C)cc2)cc1</smiles><smiles>OC(Cc1ccccc1)(c1ccccc1)c1ccccc1</smiles>

$\mathrm{PhCH}_{2} \mathrm{CH}_{2} \mathrm{Ph}$
$\mathrm{Me}_{2} \mathrm{CO}$

$\mathrm{PhCHO}$
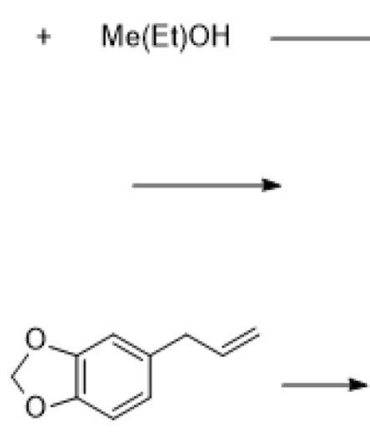

$\mathrm{PhCH}_{2} \mathrm{CH}_{2} \mathrm{Ph}$ 
Scheme 6 Unimolecular reactions of carbonyl derivatives<smiles>O=C1CCCCC1</smiles>

light<smiles>C=CCCC=O</smiles><smiles>C=C(CCCC)C(=O)O</smiles>

light<smiles>C=CCCCC(C)C=O</smiles>

light<smiles>C=CCCC(C)CC=O</smiles><smiles>C=CC(C)CCCC=O</smiles><smiles>CC1CCC(=O)CC1</smiles>

\section{light}<smiles>C=CCC(C)CCC=O</smiles>

Scheme 7 Photochemical reaction of carvone (up) and fenchone (bottom)
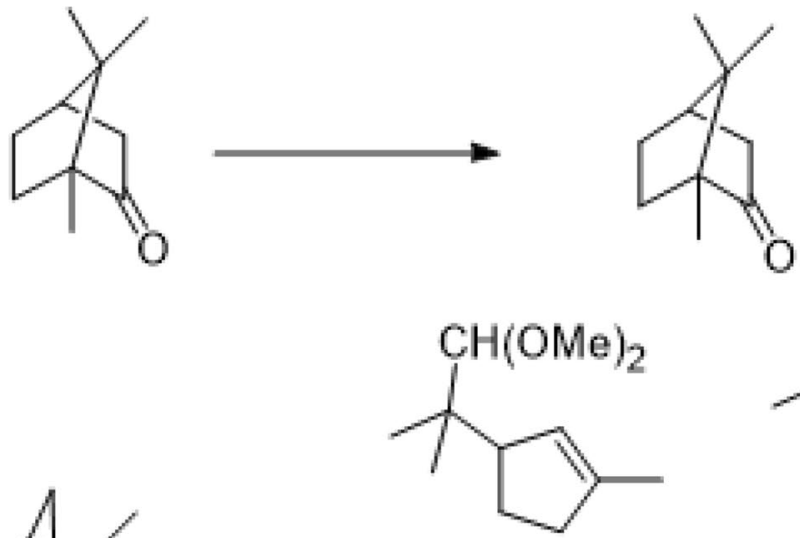<smiles>C=C(C)C1=CC(C)(C)CC1</smiles><smiles>CC1(C)CCC2CC1(C)C2=O</smiles>

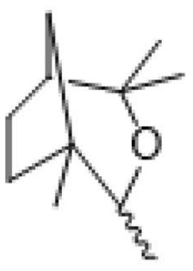


Scheme 8 Application of the photochemistry of carbonyl derivatives in step by step redox processes. Please notice the oxidation of polyols and the trapping by added reagent to obtain photochemical analogues of the Paal-Knorr and the Skraup quinoline synthesis under mild conditions<smiles>CC(C)[C@@H](O)[C@@H](CO)[C@H](C)CO</smiles><smiles>OCC1(O)OC(O)C(O)C(O)C1O</smiles>

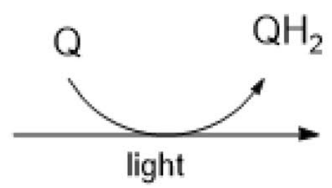<smiles>O=C1OC(O)C2(O)OC(=O)C1OC2O</smiles><smiles>O=c1[nH]c(=O)c(=O)c1=O</smiles><smiles>C[SnH3]</smiles><smiles>CC1(C)NC(=O)C(=O)C(=O)N1</smiles>

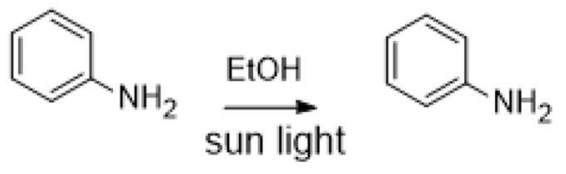

$\mathrm{MeCHO}$<smiles>Cc1ccc2ccccc2n1</smiles>

sun light<smiles>Cc1ccc2ccccc2n1</smiles>

sun light<smiles>CC(=O)C(C)C(C)C(C)=O</smiles>

Certainly, these were at the moment used for establishing the products structure, but nothing prevented their use as synthetic steps. The general knowledge of the relative yield of radicals and biradicals allowed to incorporate appropriate precursors.

This does not mean that reactions initiated as a mechanistic investigation later changed to have a significant preparative application, as is for the photochemical case discussed here, although their very nature made these processes more adaptable to changing the properties of minute amounts of a material, rather than to synthesis.
Another facet that was clear to those early researchers was the biological significance. In particular, examples of the of biological analogous reactions of redox systems included the red luminescence observed during the oxidation of pyrogallol (Scheme 10), as well as the reduction of carbon dioxide in the presence of chlorophyll under irradiation by red light, and the effect of alkaloids, and amines in general, on the photochemistry quoted by Paternò, or the formation of glycosides when non-natural [47] compounds were injected in plant cells. 
Scheme 9 Light-induced oxidation of pyrogallol to purpurogallin [48]
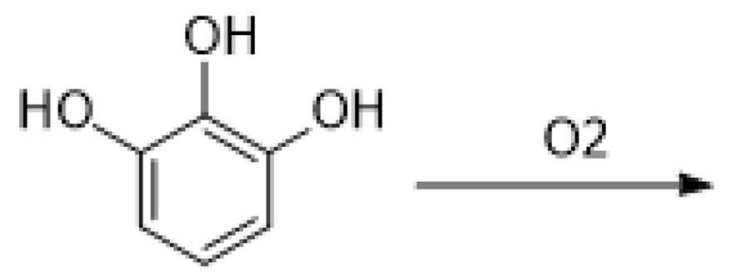

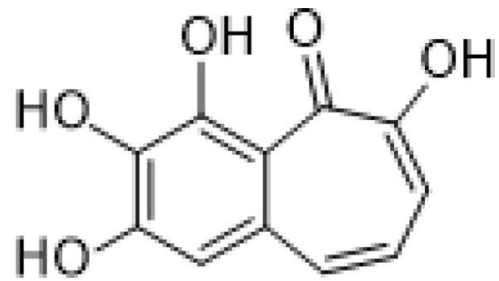

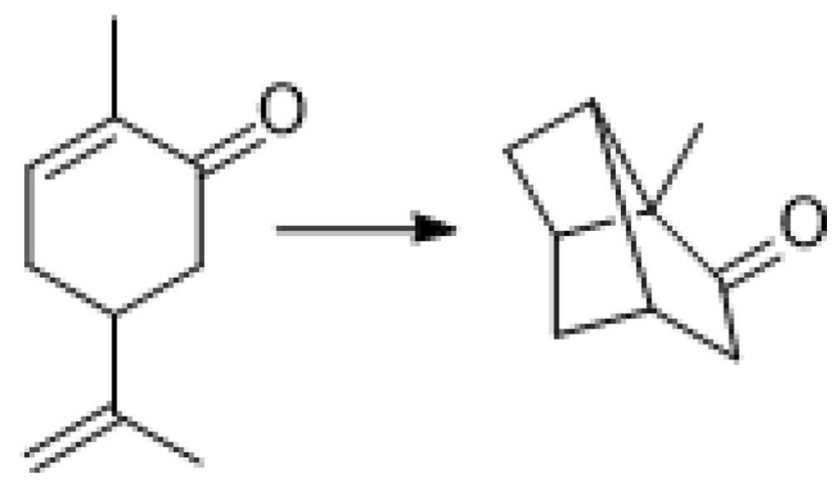

Scheme 10 Light-induced rearrangement of carvone to carvone camphor [49]

Most relevant among vegetables was the reduction of carbon dioxide to formaldehyde and its polymers, sugars, when irradiated in the presence of the green dye, chlorophyll (Eq. 1) [47].

$\mathrm{CO}_{2}+$ light, chlorophyll $\rightarrow \mathrm{CH}_{2} \mathrm{O} \rightarrow$ sugars.

Sugars irradiated. Not that the photochemistry role in redox reactions was less important, as shown in the redox chemistry in the nitrobenzene-quinone chemistry) [48] as well in the oxidative coupling of aromatic carbonyls (Scheme 9) [48].

Ciamician believed, however, that theoretical considerations were not sufficient and experience has much to tell, meaning that the photochemical science was not sufficiently developed for a sensible prediction of new processes on the basis of the rationalization of what was known. More explorative work was required for a better understanding of the 'chemical action of light'. $\gamma$-hydrogen abstraction followed by cyclization (Norrish type II- Yang). The triplet state reaction coordinates for the type I and II photochemistry were obtained computationally. While calculations predict that the type I reaction should be predominant in the triplet state due to lower barrier heights for the process, the observed reactivity in the solid-state favored the type II process. By correlating the results from calculations and experiments with singlet/triplet sensitizers/quenchers, it was found that the observed reactivity takes place along the singlet manifold.

Among the reactions considered there an exception is the intramolecular $2+2$ cycloaddition reaction involving an enone and an alkene moiety. The cyclobutane structure was proposed in a somewhat dubitative form by Ciamician in 1919 and proven to be correct only 45 years later in the same Büchi laboratory where the preparation of several oxetanes had been repeated and confirmed [49] (Scheme 10), but in this case a twofold name was not adopted, possibly because this was not the original goal of Büchi.

Interesting, and synthetically useful, variations were obtained by diverting the unimolecular reactions presented above to a different course, in particular 1,4-diradicals to other $1, \mathrm{n}$ species, by introducing reacting moieties or by carrying out the reaction in the crystal state (Schemes 11, 12) $[50,51]$. The two unpaired electrons may inhabit essentially the same region of the space is another valuable possibility, in which case the intermediate is a carbene, likewise smoothly trapped (Scheme 13).

Clearly (by now), such reactions involve both the key photochemical step and a thermal part. Therefore, product distribution changes according to conditions, see a few examples in Table 1 [52].

The conformational effects guiding the course of the intramolecular reactions have been largely investigated, in particular in the case of $\gamma$-hydrogen abstraction followed by cyclization (Norrish type II-Yang cyclization). The triplet state reaction coordinates for the Type I and II photochemistry were obtained computationally. While calculations predict that the type I reaction should be predominant in the triplet state due to lower barrier heights for the process, the observed reactivity in the solid-state showed that the predominance II process. By correlating the results from calculations and experiments with singlet/triplet sensitizers/ quenchers, it was found that the observed reactivity takes place along the singlet manifold. As an example, a highly blocked model was thus strengthening the rationalization offered by Yang of the cyclization, see Scheme 14 [53].

Since the system passes through different steps (exciplex with the alkene and diradical) there is no reason why the absolute minimum has to be reached, which strongly increases the number of attainable minima. This is a plus, and every single intermediate has to be considered for its specific role [53]. Computed evolution of various intermediates in the crystal state during irradiation is available nowadays. 
Scheme 11 Rearrangement of a 1,4 biradical leading to a carbene [50]

Scheme 12 Another reaction via 1,4-diradical and carbene [51]

Scheme 13 Photoproducts from the irradiation of 2,6-dicyclocyclohexenylcyclohexanone in the crystal state (Norrish I $\alpha$-cleavage vs Norrish II-Yang cyclization [53]. Most relevant molecule interactions are evidenced

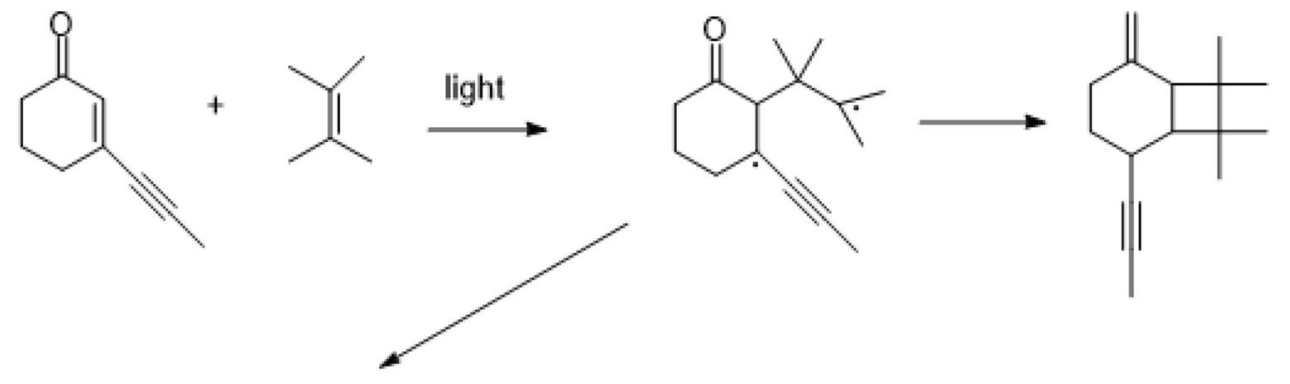<smiles>CC=CC1=C2CCCC(=O)C2C(C)(C)C1(C)C</smiles>

$+$<smiles>C=C1C2=CCCC(=O)C2C(C)(C)C1(C)C</smiles><smiles>N#CC1=CC(=O)CCC1</smiles><smiles>COC(OC)=C(C)C</smiles><smiles>COC(OC)C(C)(C)C1C(=O)CCCC1=CC#N</smiles><smiles>CC1(C)C2=C(C3=C1C(=O)CCC3)C(C(C)(C)C)CO2</smiles><smiles>COC1C(C=CC(C)C)=C2CCCC(=O)C2C(C)(C)C1OC</smiles>

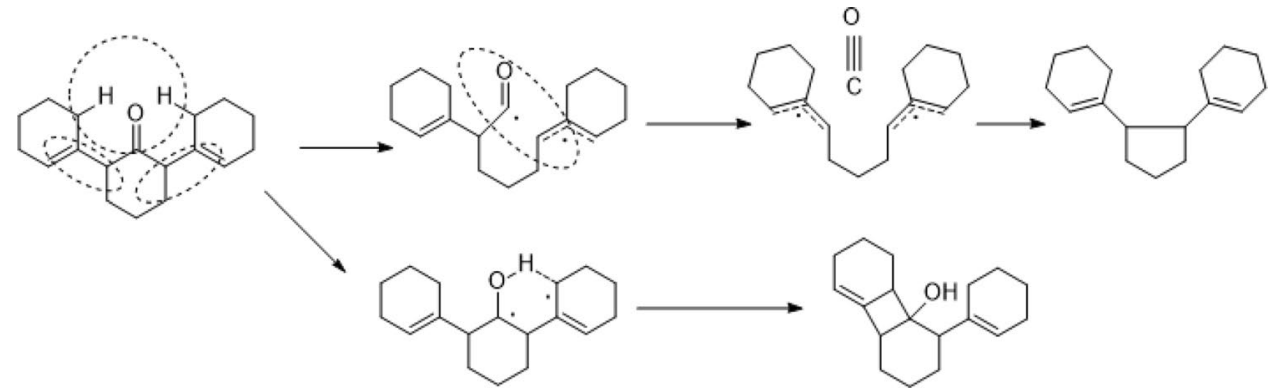


Table 1 Some quantum yield measurements [52]

\begin{tabular}{|c|c|c|c|c|}
\hline \multicolumn{5}{|l|}{ Cyclohexanone } \\
\hline $\begin{array}{l}\text { Irradiation wave length } \AA \text {, } \\
T,{ }^{\circ} \mathrm{C}\end{array}$ & $\begin{array}{l}3130 \\
125\end{array}$ & $\begin{array}{l}3130 \\
300\end{array}$ & $\begin{array}{l}2654 \\
100-300\end{array}$ & $\begin{array}{l}2537 \\
100-300\end{array}$ \\
\hline$\Phi_{\mathrm{CO}}$ & 0.22 & 0.91 & 0.78 & 0.81 \\
\hline$\Phi_{\text {ethylene }}$ & 0.02 & 0.02 & 0.02 & 0.03 \\
\hline$\Phi_{\text {propylene }}$ & 0.03 & 0.03 & 0.02 & 0.02 \\
\hline$\Phi_{\text {cyclopentane }}$ & 0.06 & 0.31 & 0.28 & 0.21 \\
\hline$\Phi_{1 \text {-pentene }}$ & 0.12 & 0.50 & 0.45 & 0.32 \\
\hline $\begin{array}{l}\Phi_{\text {polymerizzation }} \\
\text { Cyclopentanone }\end{array}$ & 0.01 & 0.02 & 0.03 & 0.25 \\
\hline $\begin{array}{l}\text { Irradiation wave length } \AA \text {, } \\
T,{ }^{\circ} \mathrm{C}\end{array}$ & $\begin{array}{l}3130 \\
125\end{array}$ & $\begin{array}{l}3130 \\
225\end{array}$ & $\begin{array}{l}2654 \\
100-300\end{array}$ & $\begin{array}{l}2537 \\
100-300\end{array}$ \\
\hline$\Phi_{\mathrm{CO}}$ & 0.33 & 0.42 & 0.61 & 0.74 \\
\hline$\Phi_{\text {ethylene }}$ & 0.15 & 0.34 & 0.25 & 0.21 \\
\hline$\Phi_{\text {cyclobutane }}$ & 0.26 & 0.17 & 0.27 & 0.21 \\
\hline $\begin{array}{l}\Phi_{\text {polimerizzation }} \\
\text { Cyclobutatnone }\end{array}$ & 0.01 & 0.10 & 0.21 & 0.34 \\
\hline $\begin{array}{l}\text { Irradiation wave length } \AA \text {, } \\
T,{ }^{\circ} \mathrm{C}\end{array}$ & $\begin{array}{l}3130 \\
100-300\end{array}$ & $\begin{array}{l}3130 \\
100\end{array}$ & $\begin{array}{l}2654 \\
100-300\end{array}$ & \\
\hline$\Phi_{\mathrm{CO}}$ & 0.35 & 0.4 & 0.53 & \\
\hline$\Phi_{\text {ethylene }}$ & 0.51 & 0.54 & 0.53 & \\
\hline$\Phi_{\text {cyclopropane }}$ & 0.13 & 0.14 & 0.17 & \\
\hline$\Phi_{\text {propylene }}$ & 0.014 & 0.014 & 0.12 & \\
\hline$\Phi_{\text {polymerizzation }}$ & 0.21 & 0.23 & 0.24 & \\
\hline
\end{tabular}

Scheme 14 Selectivity of reactions via biradicals [54].
In bimolecular reactions, already at the Ciamician and Paternò time the exploration had been extended to further donors, to begin, logically, with amines (see an example in Scheme 18 for nicotine [56]), as well as an application of rearranging skeleton with heterocycles (Scheme 18) (Fig. 2) [56].

\section{Norrish and Yang contribution}

Ronald GW Norrish (1897-1978), a professor of chemistry in Cambridge, largely contributed to the development of photochemistry and to a range of specific applicative questions of the highest relevance. Nien-chu Yang (1928-2008), a professor at the University of Chicago first reported the reaction named after him in 1958 [57].

Norrish was interested in elucidating the mechanism, as is apparent in the way he introduces his theme (as was Yang). In a typical study, Norrish investigated the photochemistry of acetone and identified the long-wavelength absorption corresponding to the $n \rightarrow \pi^{*}$ absorption $[58,59]$.

These findings confirmed those by Damon and Daniels [60] that had likewise described the visible fluorescence of acetone vapor as a greenish emission consisting of two diffuse bands, one extending from 4100 to $4820 \AA$, the other from $4990 \AA$ to the limit of the sensitivity of the plate Substituents determine the selectivity of addition either the $\mathrm{C}=\mathrm{C}$ or the $\mathrm{C}=\mathrm{O}$ bond,<smiles>[X]C1CC([R])([R])CCC1=O</smiles>

The charge transfer component is determining in the choice between $\mathrm{C}=\mathrm{C}$ and $\mathrm{C}=\mathrm{O}$ addition (Scheme 15 [53]).

In a study (see Scemes $15,16,17$ ) based on the use of potential radical clocks, it was found that vinylcyclopropane gave an adduct with a lifetime shorter than $10 \mu \mathrm{s}$, while $\omega$-pentenyl adducts essentially did not rearrange [55].

In a study using potential radical clocks as probes in the addition to cyclopentanone, both rearranged and cyclopropane ring conserving adducts were obtained, thus supporting that 1,4-diradicals live less than $10 \mu \mathrm{s}$, and evidencing that photochemistry enjoys from the control on still another (beside the irradiation wavelength) further dimension, time [55]. On the other hand, the topochemical principle has been largely applied for the photochemistry in the crystals, offering a range of examples with an exquisite control of competing path, e.g. Norrish Type I vs Type II, as well of predictions based on calculations (Schemes 16, 17).

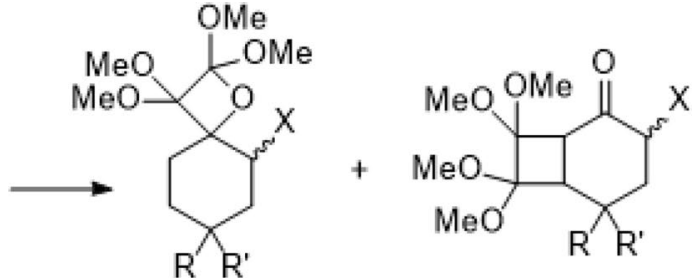

(5210 ̊). They recorded that the intensity was reduced and the color of the fluorescence changed to the blue upon the addition of oxygen or air, but that the bright green fluorescence was restored after a period of illumination. These changes were readily explained by the specific quenching action of oxygen due to photochemical oxidation, which is known to occur under these conditions. The excited molecules of acetone upon reaction lost their power to fluoresce, while the blue fluorescence is the product of a transient intermediate compound present during the process of oxidation (Fig. 3).

This sequence of operations was repeated several times before the heating current was switched on to stir the liquid in the reaction cell. With the liquid boiling from two hot spots, the process was then repeated a further three times over a period of $30 \mathrm{~min}$, after which time it was found that all the dissolved gases had been expelled from the solution, 
Scheme 15 Expected products from the addition of vinylcyclopropane and 2-cyclopentenone [55]

Scheme 16 Expected adducts from cyclopentanone and hexadiene 55
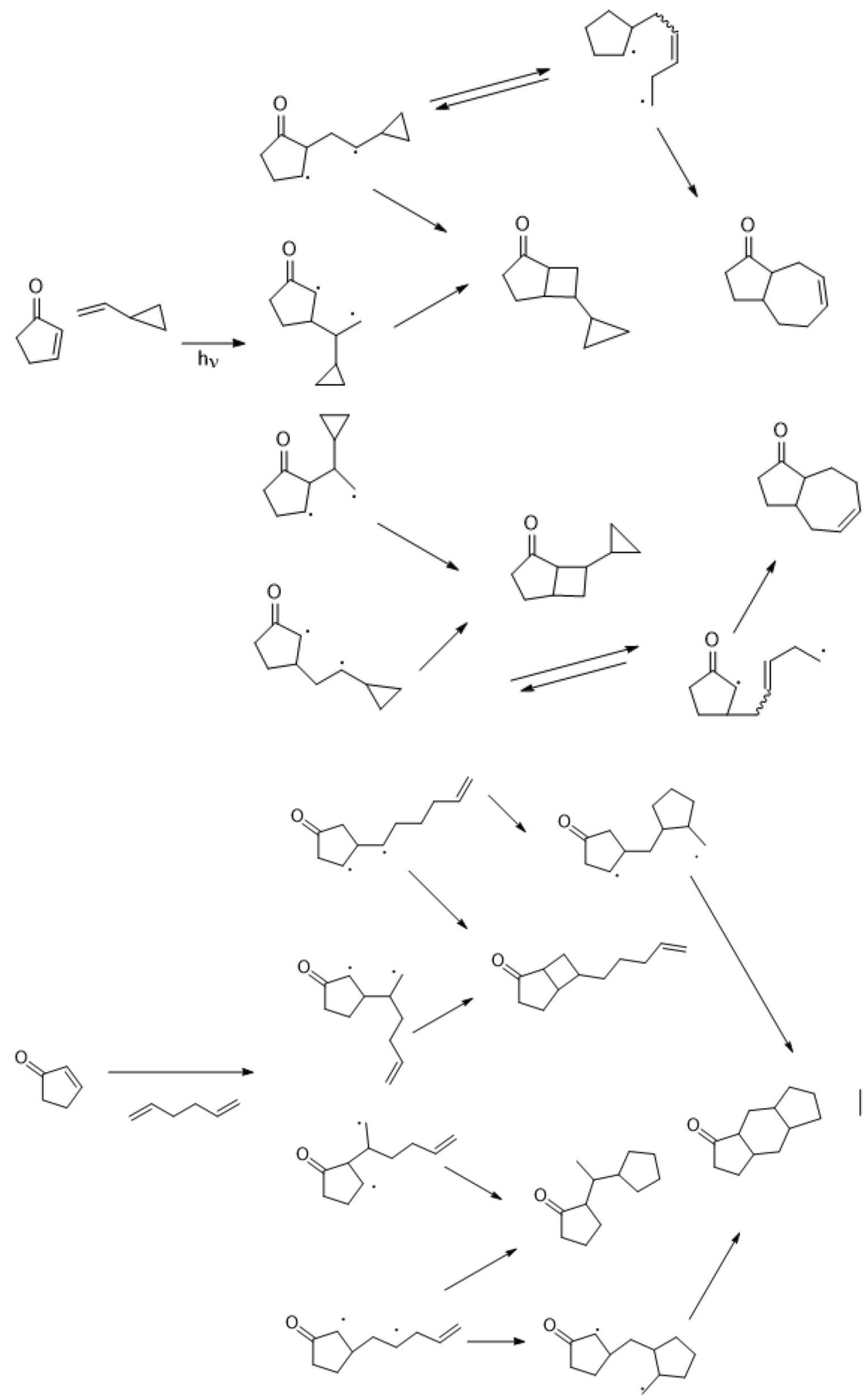

Gas evolved during irradiation was removed by manipulation of the Toepler pumps without interrupting the experiment and stored in either of the vessel E or F. At the
The filtered light was then allowed to pass through the cell for the ti445me necessary to produce the decomposition recorded in Table 1. 
Scheme 17 Expected Adducts from the addition of 2-cyclopentenone and vinylcyclopropane [55]

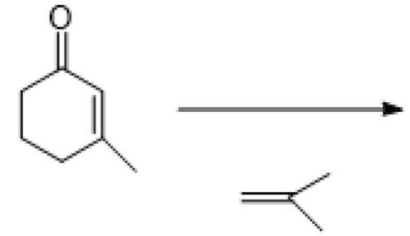<smiles>C=C(C)CC1C(=O)CCCC1C</smiles>

$0 \%$<smiles>CC1CCCC(=O)C1C(C)(C)C</smiles><smiles>C=C(C)CC1(C)CCCC(=O)C1</smiles>

Scheme 18 Coupling between nicotine and benzophenone [56]<smiles>CN1CCCC1c1cccnc1</smiles>

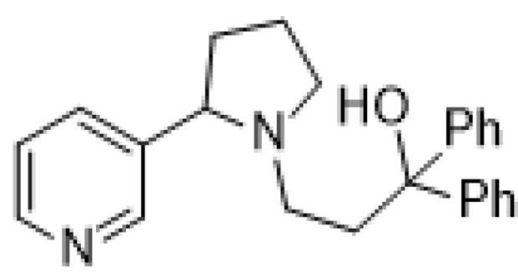

conclusion of each experiment the liquid nitrogen surrounding the cooling coil was replaced by a mixture of dry ice and ethyl alcohol, and any substance volatile at this temperature was transferred to the storage vessel. Finally, the small amount of solvent, which was invariably carried over by the gas into the coil was distilled back into the reaction vessel. This was then removed from the system and the contents analysed (Fig. 4).

Of the very large scientific output by Norrish, only a little more than 10 papers are devoted to the photochemistry of ketones. These lead to the same results as those previously reported by Ciamician and Paternò, with a more precise assessment of competing paths, as was easily done by vpc, but omitting most of the aromatic compounds due to their low volatility. The $2+2$ cycloaddition was for the first time reported after the Second World War by Yang, likewise as a way to improve the rationalization of the carbonyl photoreactions, even if he later strengthened the preparative aspect that were considerably developed [63].

To understand the largeness of the Rubicone river that Norrish had to bring over the chemical community one should think how difficult it had been for chemists to accept the idea that the primary quantum yield, i e, the sum of the yield of decay for all of the decay modes of the excited states had to be unitary, as it has been predicted by Einstein. A Royal Society of Chemistry-organized meeting had been devoted exactly to this topic in 1926 [64], but most or the attendees did not concur with the view of the validity of the equivalence law, while 20 year later no one disputed such a representation and intermediates were measured, indeed a specific apparatus had been (home) made, flash photolysis, and had been instrumental in causing such a shift. Even more important for chemistry was that new intermediates, free radicals came out and their spectrum and lifetime were measured. (Free) radicals came to the center of the stage and became ubiquitous intermediates of organic reactions.

Norrish type I reaction ( $\alpha$ bond cleavage) under collisionfree conditions yields free radical species, whose stability will depend on the degree of substitution and the nature of the substituent(s) near the radical sites (specifically at the substituent labelled as R1, R2 and R3 in Scheme 19 [65] stabilized more or less the radicals through steric and/or polar effects while leaving also a possible non-radiative 'all 


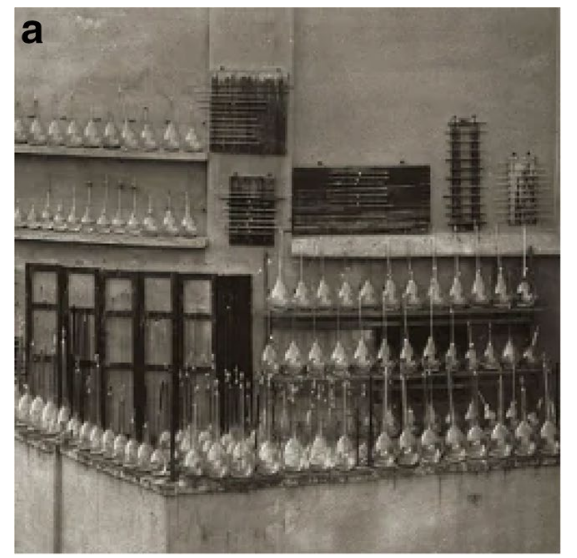

b

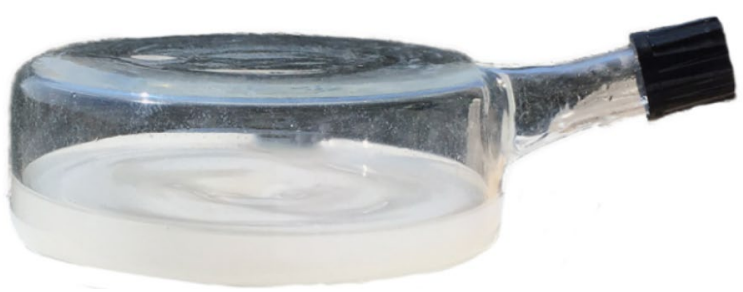

Fig. 2 a Typical flasks Ciamician used for his exploratory studies of the solar light effect, as well as $\mathbf{b}$ smaller flat flasks used for window still photochemistry also in the presence of a solid photocatalyst singlet state' route leading back to the S0 state or to alternative rearrangement paths, which can be expected to become increasingly important in collisional environments - especially in appropriately substituted carbonyls. The $\gamma$-hydrogen abstraction might thus be followed by diradical fragmentation ( $\mathrm{C} \beta-\mathrm{C} \gamma$ bond, Norrish II) or by the formation of a new bond (to give a hydroxycyclobutane, Yang reaction, compare Scheme 20) [63].

However, this discipline had made no big advancements yet, Ciamician opined that this was, because of insufficient mechanistic insight [28]. The only photochemical phenomena that had been studied in detail had been those connected with photography (see above). Thus, Wildemann had confirmed the proportionality between photochemical reaction and light intensity postulated by Bunsen and Roscoe [44]. The rather uncommon instance of a photochemical reaction that was reversed in the dark had been demonstrated in a number of cases, such as the reversible isomerization of fulgides investigated by Stobbe [45].

This does not mean that reactions initiated as the mechanistic investigation could later be shifted to have a significant preparative application, as is the case for the photochemical reactions discussed here.

The impressive science developed by Norrish involves both the study of the mechanism of basic reactions, not only photochemical but also thermal, including important

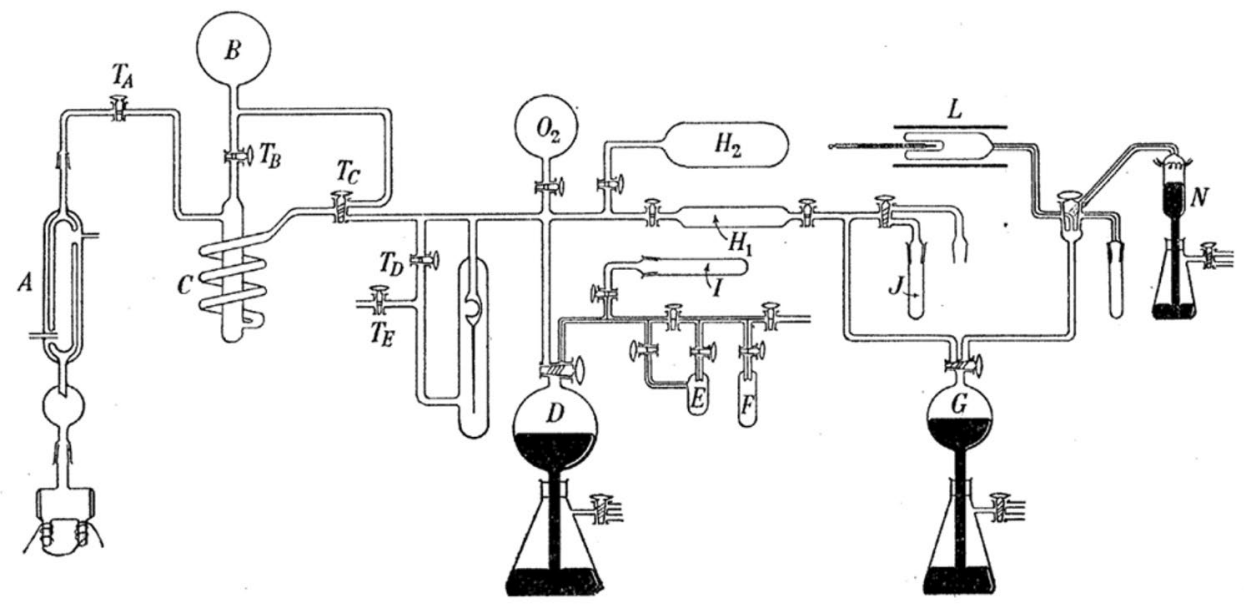

Fig. 3 Schematic view of an apparatus used by Norrish for the separate collection of photoproducts at different temperatures. At the start of an experiment [61, 62], $60 \mathrm{ml}$ of peroxide solution was pipetted into the reaction vessel which was them connected to the groundglass joint at the lower end of the condenser. A. The procedure employed to degas the solution was as follows. The coil $\mathrm{C}$, which was surrounded by a Dewar flask containing liquid air, was connected to the $400 \mathrm{ml}$ bulb B by means of tap TC, tap TB being kept closed. Tap TA was then opened momentarily, allowing the air in the condenser and reaction vessel to pass into the bulb via the cooling coil. The twoway tap TC was then reversed and with both taps TB and TD open, the air was drawn from the bulb, through the cooling coil for a second time, and pumped away via tap TE 


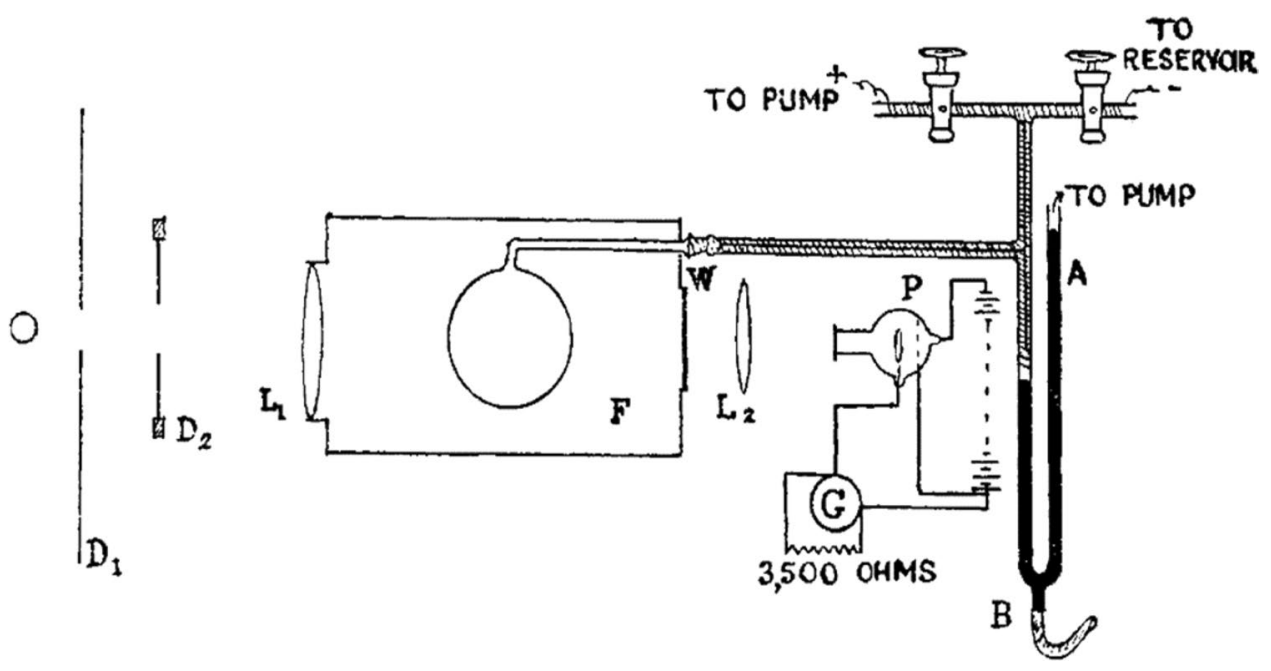

Fig. 4 Schematic view of the apparatus used by Norrish for measuring quantum yields. The diaphragm D1, with an aperture of $2 \mathrm{~cm}$., was as close to the lamp as possible, and about $5 \mathrm{~cm}$. in front of D1 was another diaphragm D2, also of about $2 \mathrm{~cm}$. aperture. After D2 the light fell on a large quartz lens L1 (of $10 \mathrm{~cm}$. focal length and at $18 \mathrm{~cm}$. from $\mathrm{Dl}$ ), entered the furnace, and passed through the reaction vessel, coming to a focus near the far end of F. After traversing the quartz window $\mathrm{W}$, it was made to converge again by the quartz lens
L2 (6 cm. focal length), so that it fell on the photoelectric cell P. The cell was first calibrated directly for the light of wave-lengths 436 and $365 \gamma \gamma$ by comparison with a thermopile circuit, of which the energysensitivity had been accurately determined by means of a standard carbon-filament lamp supplied by the National Physical Laboratory. The energy sensitivity at 313 and $256 \mathrm{~nm}$ was then obtained relative to that at 436 and $365 \mathrm{~nm}$ by comparison of the four wavelengths, a monochromator and thermopile being used [62]
Scheme 19 The light-absorbing moiety and the reacting molecules can be differently located

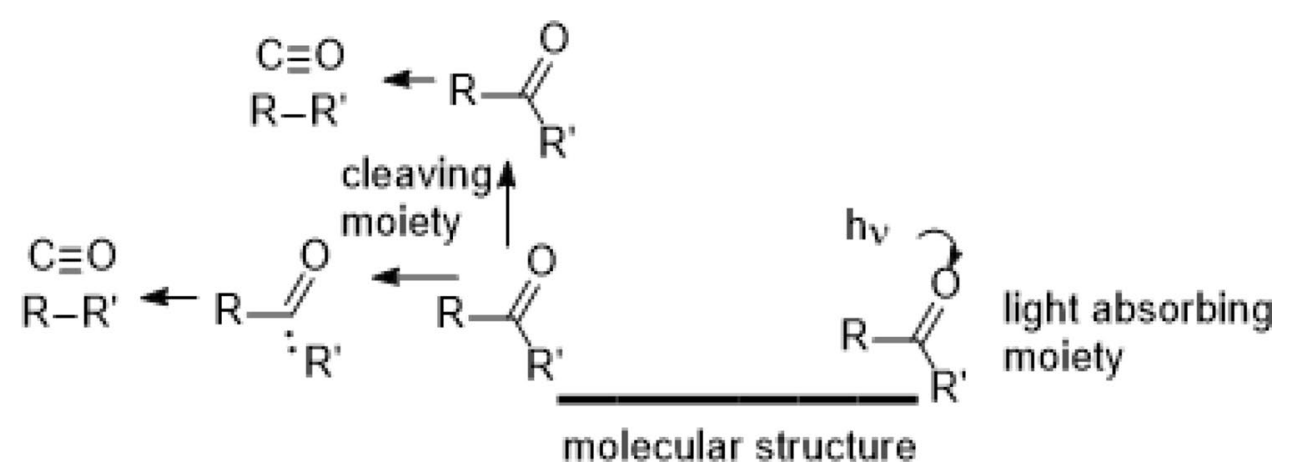

application in technical issues, such as the reactions in the flame and in the explosion and knock mechanism and the addition of anti knock [66] agents and the chain regulating effect such agents exerted on reactions occurring in a flame and in explosions.

The research by Norrish follows a well-differentiated path, pointed to clarify the mechanism. Most of the reactions he studied involve a cleavage of a bond and generating a pair of radicals (or a biradical). The reacting moiety can well involve a different location as the light-absorbing chromophore. Such an intramolecular energy transfer process is similar to a type I intramolecular collision.

Norrish took a fully different approach by evidencing as much as possible the structure and lifetime of intermediates. A quite strong flash allowed to excite 'simultaneously' a large number of molecules and thus of radicals if these were reasonable intermediates. The short lifetime required a different approach, otherwise their concentration would remain always too low. Norrish developed a peculiar system, where a powerful flash was caused by discharging a charge from a condenser and a second exploring flash was used to monitor the short-lived species and their decay was easily monitored due to their strong absorbance in the visible range [67, 68] (Fig. 5).

In his laboratory, Norrish studied both fundamental oxidation processes and important applicative reactions that affect the everyday life of each of us, in particular the effect of anti-knock agents for the regulation of chain processes in fuel, as well as polymerization processes, both for generating the linear chain [69-75], for cross-linking [76-81], for catalyzed processes involving polymers [82-90] and for forming graft and block copolymers [91] (Fig. 6).

To summarize, the attribution of the two name reactions to Norrish adds little to the fame of the scientist, but it is 
Scheme 20 Intramolecular reactions of carbonyl derivatives, up, alphacleavage, and gamma-hydrogen transfer<smiles>[R]C(=O)C([R])([R])[R]</smiles><smiles>[R]C([R])([R])[13CH][13CH]</smiles><smiles>[R]C=O</smiles><smiles>[R]C([R])=C([R])[R]</smiles>

Fig. 5 Visible absorption spectra of some radicals $[67,68]$
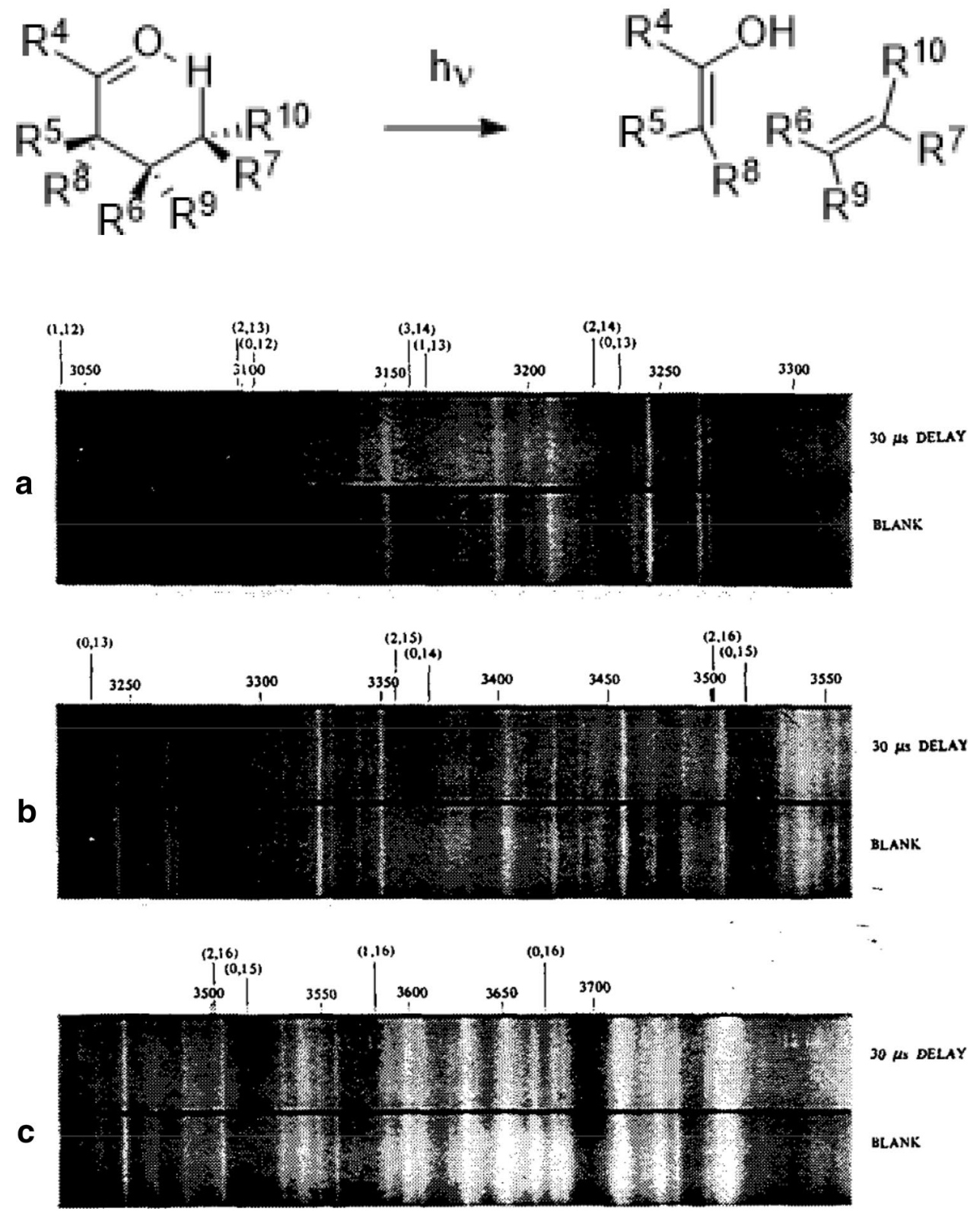

too late to redress the situation, and the course of the reaction occurring is that indicated in Scheme 1. The important fact is that the photocycloaddition, not considered in Scheme 1 , has greatly developed in the last two decades both the intra- and intermolecular version, becoming the most relevant process in retrosynthetic planning, with the distinction of further side processes. In turn considered name reactions, in particular, the de Mayo reaction. The reaction answers to 


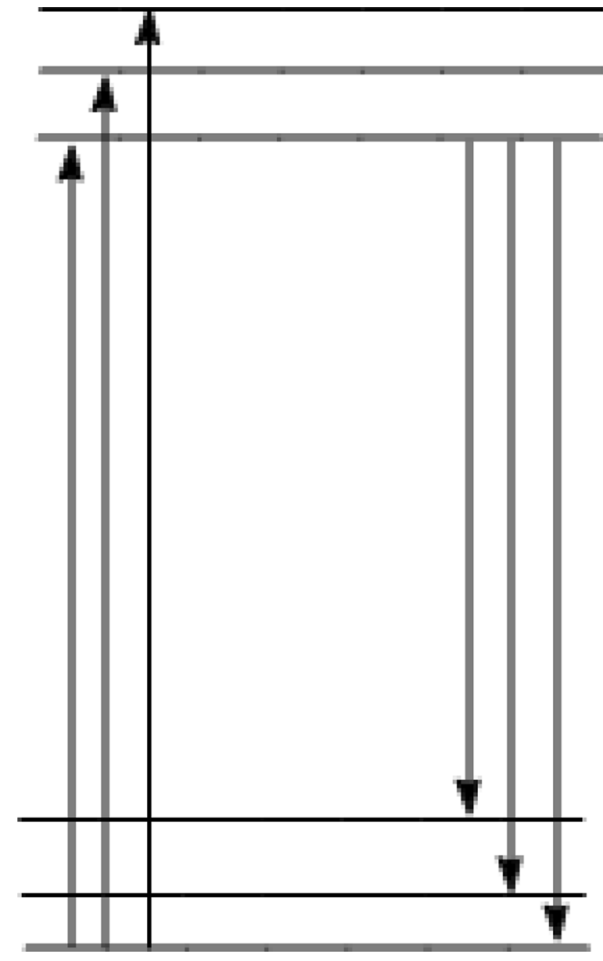

Fig. 6 Light absorbance leads from the ground electronic and vibrational zeroth state up to the electronically and vibrationally excited states $\left(S_{00}\right)$, while emission leads back to the ground state as well as to states with further vibrational components $\left(S_{\text {on }}\right)$

the ideal case for a 'clean' photochemical process, with the reagent strongly absorbing over the UVA wavelength range, while the products absorb only weakly in the UV-B region. Furthermore, the UVA present I solar light is sufficient for converting an amount of about $100 \mathrm{mg}$ in a few hours.

\section{Conclusions}

A process that Ciamician found remained out of the general synthetic scheme and this was the intramolecular $2+2$ cycloaddition of carvone to yield carvone camphor (Scheme 8) [49] that was to become one of the most popular topics in photochemistry. The reaction answers to the ideal case for a 'clean' photochemical process, with the reagent strongly absorbing over the UVA wavelength range, while the products absorb only weakly in the UV-B region. Furthermore, the UVA present I solar light is sufficient for converting an amount of about $100 \mathrm{mg}$ in a few hours at no cost, and alternatively inexpensive lamps are readily available and are conveniently used with microreactors.

Norrish has certainly been a major contributor to photochemistry. Indeed, his clear description of excited states and their chemistry find a parallel only in GN Lewis papers, and finally overcomes a gap between chemistry and physics that had lasted 20 years, after the Einstein contributions. Remaining on the chemical side, photo chemists had now to bring such reactions within the synthetic arena, where the kinetic approach by Norrish was not productive and here the unicity of the $2+2$ cycloaddition of carvone was remarked by Prof Schönberg when compiling the first book on organic photochemistry and he proposed to add this reaction to the repertoire and to name it the 'Ciamician' reaction, but his proposal did nor find interest and Ciamician-s primary is only sparsely quoted.

Apparently, a barrier between physical chemistry (studying the mechanism of reactions already known, and synthetic chemistry, which provided examples, was not the best choice, and an interdisciplinary one was much better when it became accessible through the progress in computational. The most relevant process in retrosynthetic planning, with the distinction of further related processes that have been considered name reactions, in particular the de Mayo reaction [92-94], arriving nowadays at a galaxy of diverse and versatile reactions [96-98]. Nor has the environmentfriendly character of his reaction been lost, on the contrary it has been clearly documented [99-120].

The reaction answers to the ideal case for a 'clean' photochemical process, with the reagent strongly absorbing over the UVA wavelength range, while the products absorb only weakly in the UV-B region. Furthermore, the UVA present in solar light is sufficient for converting an amount of about $100 \mathrm{mg}$ in a few hours and us easily developed up to about $100 \mathrm{~g}$.

This topic is perhaps the nicest example of the essential dichotomy that characterizes photochemistry and makes it that exciting this science, equally for physical chemists and synthetic chemists. In different times, there has been a predominating role of either group in this field, and this has perhaps led to some misunderstanding but has finally resulted in an increased advancement of this interdisciplinary science.

The old Ciamiciamn reactions and their methodology had again become on the forefront of research with the advent of 'green' chemistry, where his methods have been found to fit easily with the requirements of that topic and have become a favorite ground for testing flow conditions [101-107] in microreactors and for photocatalytic processes including those involving visible light.

\section{References}

1. Hassner, A., \& Namboothiri, I. (2011). Organic Synthesis Based on Name Reactions (3rd ed.). Amsterdam: Elsevier.

2. Li, J. J. (2009). Name Reactions: A Collection of Detailed Reaction Mechanisms (4th ed.). Berlin: Springer.

3. Kürti, L., \& Czakó, B. (2005). Strategic Applications of Named Reactions in Organic Synthesis. Amsterdam: Elsevier. 
4. Wang, Z. (2009). Comprehensive Organic Name Reactions and Reagents. Hoboken: Wiley.

5. Papeo, G., \& Pulici, M. (2013). Italian chemists' contributions to named reactions in organic synthesis: An historical perspective. Molecules, 18, 10870-10900.

6. IUPAC Gold Book, "Orrish Type I Photoreaction", Gold Book.

7. IUPAC Gold Book, "Norrish Type II Photoreaction" Gold Book.

8. The Nobel prize in Chemistry, 1967 , nobelprize.org.

9. Bloodworth, S. (2019). Norrish Photolytic Cleavage. RSC: Chemword.

10. Diau, E. W. G., Kőtting, C., \& Zewail, A. H. (2001). Femtochemistry of norrish type-I reactions: I. Experimental and theoretical studies of acetone and related ketones on the S1 surface. ChemPhysChem, 5, 23-293.

11. Paternò, E., \& Villavecchia, V. (Eds.). (1907). Atti del VI Congressointernazionale di chimica applicata, 7 vol. Bertero: Tipografia nazionale diG.

12. Foley, L. Interview to Professor Buchi, MIT/Chemistry.

13. Ciamician, G., \& Silber, P. (1900). Chemische Lichtwirkurgen. Berichte der Deutschen Chemischen Gesellschaft, 1900, 2911-2913.

14. Paternò, E. (1909). Organic syntheses induced by light. Introductory note. Gazzetta Chimica Italiana, 39, 237-250.

15. Albini, A. (2016). Photochemistry. Past, Present and Future. Heidelberg: Springer.

16. MacLafferty, F. (1959). Mass spectrochemical analysis. Molecular rearrangement. Analytical Chemistry, 31(1), 82-87.

17. Ramamurthy, V., \& Venkatesan, K. (1987). Photochemical reactions of organic crystals. Chemical Review, 87, 433-481.

18. Veerman, M., Resendiz, J. E. M., \& Garcia-Garibay, M. A. (2006). Large-scale photochemical reactions of nxanocrystalline suspensions: A promising green chemistry method. Organic Letters, 8, 2615-2617.

19. Schuster, D. L., Greenberg, M. M., Nunez, I. M., \& Tucker, P. C. (1983). Identification of the reactive electronic excited state in the photocycloaddition of alkenes to cyclic enones. Journal of Organic Chemistry, 48, 2615-2619.

20. Heidel, N. D., \& Pfau, M. A. (1965). A profitable partnership-Giacomo Ciamician and Paul Silber. Journal of Chemical Education, 42, 383-387.

21. D'Auria, M. (2013). On a dispute between Ciamician and Paternò. EPA Newsletter, 84(106-109), 21.

22. Albini, A., \& Dichiarante, V. (2009). The 'belle époque' of photochemistry. Photochemical \& Photobiological Sciences, $8,248-254$

23. Ciamician, G., \& Silber, P. (1902). Azioni chimiche della luce. Nota III. Rendiconti Matematica Accademia dei Lincei, 11(5), 277-284.

24. Ciamician, G. L., \& Dennstedt, M. (1881). Ueber die Einwirkung des Chloroforms auf die Kaliumverbindung Pyrrols. Berichte der Deutschen Chemischen Gesellschaft, 14, 1153-1162.

25. Friedburg, L. H. (1899). On recent progress in photochemistry. Journal of the American Chemical Society, 21(445), 250.

26. Ciamician, G. (1908). Actions chimiques de la lumière. Bulletin de la Société Chimique de France, 4, i-xxiii.

27. Albini, A., \& Fagnoni, M. (2008). Giacomo Ciamician and the concept of green chemistry. Chemsuschem, 1, 63.

28. Ciamician, G. (1912). The photochemistry of the future. Science, 36, 385.

29. Paternò, E., \& Villavecchia, V. (1907). Atti del VI Congresso internazionale di chimica applicata. Roma: Tipografia nazionale di G. Bertero.

30. Ciamician, G., \& Silber, P. (1909). Chemical actions of light. XIV. Ber Chem Dtsch Ges, 42, 1386-1391.
31. Paternò, E., \& Traetta-Mosca, F. (1911). Synthesis in organic chemistry by means of light. III. Isoamylbenzoketones and some physical constants of the compounds of amylene with benzaldehyde and ketones. Gazzetta Chimica Italiana, 39(1), 449-454.

32. Ciamician, G., \& Silber, P. (1915). Sintesi in chimica organica per mezzo della luce. Nota V. Comportamento degli acidi e degli eteri col benzofenone. Gazzetta Chimica Italiana, 40(II), 321-331.

33. Paternò, E. Inaugural address, International Conference in Chemistry, Rome,1906 (refers to the address delivered to the delegates to the previous conference in London in 1904).

34. Ciamician, G., \& Silber, P. (1914). Chemical actions of light. XIV. Auto-oxidations. V. Ber Chem Dtsch Ges, 46, 3077-3084.

35. Ciamician, G., \& Silber, P. (1910). Chemical actions of light. XVI. Ber Chem Dtsch Ges, 43, 1340-1350.

36. Paternò, E., \& Chieffi, G. (1911). Synthesis in organic chemistry by means of light. IV. Action of paraffins and of benzene homologs on ketones and aldehydes. Gazzetta Chimica Italiana, 39(2), 415-435.

37. Büchi, G., Inman, C. J., \& Lipinsky, E. S. (1954). Light-catalyzed organic reactions. I. The reaction of carbonyl compounds with 2-methyl-2-butene in the presence of ultraviolet light. Jounal of American Chemical Society, 76, 4327-4331.

38. Ciamician, G., \& Silber, P. (1910). Chemical actions of light. XVI. Ber chem dtsch Ges, 43(945-949), 38.

39. Ciamician, G., \& Silber, P. (1905). Chemical actions of light. X. Ber chem dtsch Ges, 38, 3813-3824.

40. Ciamician, G., \& Silber, P. (1908). Chemical actions of light. XIII. Ber chem dtsch Ges, 41, 1928-1935.

41. Schőnberg, A. (1968). Preparative Organic Photochemistry. Berlin: Springer.

42. Plotnikov, I. S. (1920). Allgemeine Photochemie, ein Hand- und Lehrbuch für Forschung. Berlin: Praxis und Studium.

43. de Saint-Victor, N. (1856). Traité Practique de Gravure Héliographique sur Acier et sur Verre. Paris: V Masson.

44. Bunsen, R. W., \& Roscoe, H. E. (1862). Photochemical researches - Part V. On the measurement of the chemical action of direct and diffuse sunlight. Proceeding of the Royal Society, $12,306-312$.

45. Stobbe, H. (1908). Phototropie Erscheinungen bei Fulgiden und anderen Stoffen. Liebigs Annalen der Chemie, 359, 1-48.

46. Ciamician, G., \& Silber, P. (1907). Chemical actions by light XI. Ber chem dtsch Ges, 40, 2415-2424.

47. Ciamician, G., \& Ravenna, C. (1909). Sulla formazione dei glucosidi per mezzo delle piante. Rendiconti Matematica Accademia dei Lincei, 18, 594-596.

48. Critchlow, A., Haslam, E., Haworth, P. B., Tinker, P. N., \& Waldron, N. M. (1967). The oxidation of some pyrogallol and purpurogallin derivatives. Tethraedron, 23, 2829-2847.

49. Buchi, G., \& Goldman, I. M. (1957). Photochemical reactions, II. The intramolecular cyclization of carvone to carvonecamphor. Journal of American Chemical Society, 79, 4741-4748.

50. Agosta, W. C., \& Margaretha, P. (1996). Exploring the 1,5 cyclization of alkyl propargyl 1,4 biradicals. Accounts of Chemical Research, 29, 179-182.

51. Rathjen, H.-J., Margaretha, P., Wolff, S., \& Agosta, W. C. J. (1991). a3904Novel [3+2] photocycloaddition of 3-(1-alkynyl)2-cycloalken-1-ones with alkenes. American Chemical Society, $113,1$.

52. Blacet, F. E., \& Miller, A. (1957). The photochemical decomposition of cyclohexanone, cyclopentanone and cyclobutanone, 1957. Journal of the American Chemical Society, 79, 4327-4329.

53. Campos, L. M., Mortko, C. J., \& Garcia-Garibay, M. A. (2006). Norrish type I vs. norrish-Yang type II in the solid state photochemistry of cis-2,6-di(1-cyclohexenyl)-cyclohexanone: A 
computational study. Molecular Crystal and Liquid Crystal, 456, $15-24$.

54. Cruciani, G., Rathjen, H., \& Margaretha, P. (1990). Photocycloaddition of cyclohex-2-enones to tetramethoxyethylene: Formation of 2,2,3,3-tetramethoxy-1-oxaspiro[3.5]nonenes. Helvetica Chimica Acta, 73, 856-869.

55. Rudolph, R., \& Weedon, A. C. (1990). Radical clocks as probes of 1,4-biradical intermediates in the photochemical cycloaddition reactions of 2-cyclopentenone with alkenes. Canadian Journal of Chemistry, 68, 1160-1967.

56. Paternò, E., Chieffi, G., \& de Fazi, R. (1914). Effetto della luce su alcaloidi vegetali. Gazzetta Chimica Italiana, 44(II), 99-111.

57. Yang, N. C., \& Yang, D. D. H. (1958). Photochemical reactions of ketones in solution. Journal of the American Chemical Society, 76, 291358.

58. Crone, H., \& Norrish, R. G. W. (1933). Predissociation in a fluorescence emission spectrum. Fluorescence of acetone vapors. Nature (London, United Kingdom), 132, 241.

59. Norrish, R. G. W., \& Saltmarsh, O. D. (1934). Primary photochemical reactions. Part V. The spectroscopy and photochemical decomposition of acetone. Journal of Chemical Society, 5, 1456-1464.

60. Damon, G. H., \& Daniels, F. (1933). The photolysis of gaseous acetone and the influence of water. Journal of American Chemical Society, 55, 2363-2369.

61. Martin, J. T., \& Norrish, R. G. W. (1953). The photochemical decomposition of t-butyl hydroperoxide in solution. Proceeding of the Royal Society London A, 220, 322-339.

62. Norrish, R. G. W., \& Kirkbride, F. W. (1932). Primary photochemical processes. Part I. The decomposition of formaldehyde. Journal of the Chemical Society, 135, 1518-1530.

63. Chen, C. (2014). The past, present, and future of the Yang reaction. Organic and Biomolecular Chemistry, 14, 8641-8647.

64. Franck, J., \& Dymond, E. G. (1926). Elementary processes of photochemical reaction. Transactions on Faraday Society, 21, 536-542.

65. De Feyter, S., Zewail, A. H., \& Diau, E. W. G. (2000). Femtosecond dynamics of Norrish Type-II reactions : Nonconcerted hydrogen-transfer and diradical intermediate. Angew Chemie International Edition, 39, 260-263.

66. Callear, A. B., \& Norrish, R. G. W. (1960). The behaviour of additives in explosions and the mechanism of antiknock. Proceedings of the Royal Society of London Series A Mathematical and Physical Sciences, 259(1298), 304-324.

67. Norrish, RGW, Some fast reactions in gases studied by flash photolysis and kinetics spetroscopy, Nobel Lecture, December 11, 1967.

68. Thompson, H. W., \& Frewing, J. J. (1935). Absorption Spectra of Substances containing Alkyl Radicals. Nature (London, United Kingdom), 135, 507-508.

69. Mullik, S. U., \& Norrish, R. G. W. (1975). Photolysis of poly(vinyl bromide). Proceedings of the Royal Society of London, Series A: Mathematical, Physical and Engineering Sciences, 344(1636), 1-19.

70. Mullik, S. U., \& Norrish, R. G. W. (1963). Kinetic studies with a Ziegler catalyst system in the gaseous phase. Proceedings of the Royal Society of London, Series A: Mathematical, Physical and Engineering Sciences, 275(1362), 310.

71. Hussain, F., \& Norrish, R. G. W. (1963). The photoinitiation of the polymerization of vinyl compounds by means of cerous ions. Proceedings of the Royal Society of London, Series A:Mathematical, Physical and Engineering Sciences, 275(1361), 161-170.

72. Mullik, SU, Norrish, RGW. Photopolymerization, 1959, US 290242119.
73. Guillet, JR. The photolysis of polymethyl vinyl ketone. II. The preparation of graft polymers.

74. Guillet, JE, Norrish, RGW. Photolysis of poly methyl vinyl ketone: formation of block polymer. The mechanism and kinetics of the heterogeneous polymerization of vinyl monomers. II. The benzoyl peroxide-catalyzed polymerization of vinylidene chloride.

75. Bengough, W. I., \& Norrish, R. G. W. (1953). A new catalytic effect in vinyl polymerization. Proceedings of the Royal Society of London, Series A: Mathematical, Physical and Engineering Sciences, 218, 149-154.

76. Guillet, J. E., \& Norrish, R. G. W. (1955). The photolysis of polymethylvinylketone. I. Reactions and kinetics. Proceedings of the Royal Society of London, Series A: Mathematical, Physical and Engineering Sciences, 233, 172-183.

77. Guillet, J. E., \& Norrish, R. G. W. (1955). The photolysis of polymethyl vinyl ketone. I. Reactions and kinetics. Proceedings of the Royal Society of London Series A: Mathematical, Physical and Engineering Sciences, 233, 153-157.

78. Knox, K., Norrish, R. G. W., \& Porter, G. (1952). The photochemical decomposition of ketene by means of light of very high intensity. Journal of the Chemical Society, 1, 1447-1486.

79. Bevington, J. C., \& Norrish, R. G. W. (1949). Cross-linking of vinyl polymers by Friedel-Crafts catalysts. Journal of the Chemical Society, 1, 482-485.

80. Norrish, R. G. W., \& Brookman, E. F. (1937). The formation and structure of polymers of the insoluble cross-linked type. Proceedings of the Royal Society of London, Series A: Mathematical, Physical and Engineering Sciences, 163, 205-220.

81. Bevington, J. C., \& Norrish, R. G. W. (1948). The cross-linking of vinyl polymers by Friedel-Crafts catalysts. Journal of the Chemical Society, 1, 771-774.

82. Nicholson, A. E., \& Norrish, R. G. W. (1956). Polymerization of styrene at high pressures using the sector technique. $R G W$ Discussion Faraday Society, 22, 104-113.

83. Bevington, J. C., \& Norrish, R. G. W. (1951). The catalyzed polymerization of gaseous formaldehyde. Proceedings of the Royal Society of London Series A: Mathematical, Physical and Engineering Sciences, 205, 516-529.

84. Bengough, W. I., \& Norrish, R. G. W. (1950). Mechanism and kinetics of the heterogeneous polymerization of vinyl monomers. I. Benzoyl peroxide-catalyzed polymerization of vinyl chloride. Proceedings of the Royal Society of London, Series A: Mathematical, Physical and Engineering Sciences, 200, 301-320.

85. Bevington, J. C., \& Norrish, R. G. W. (1949). The polymerization of acetaldehyde at low temperatures. Proceedings of the Royal Society of London, Series A: Mathematical, Physical and Engineering Sciences, 196, 363-378.

86. Bengough, W. I., \& Norrish, R. G. W. (1949). New catalytic effect in vinyl polymerizations. Nature (London, United Kingdom), 163, 325-326.

87. Norrish, R. G. W., \& Smith, R. R. (1942). Catalyzed polymerization of methyl methacrylate in the liquid phase. Nature (London, United Kingdom), 150, 336-337.

88. McDonald, R. D., \& Norrish, R. G. W. (1936). Photochemical reactions in the fluorite region. I. Photochemical decomposition of ethylene. Proceedings of the Royal Society of London Series A: Mathematical, Physical and Engineering Sciences, 157, 480-490.

89. Carruthers, J. E., \& Norrish, R. G. W. (1935). Polymerization of formaldehyde. Nature (London, United Kingdom), 135, $582-5833$.

90. Norrish, R. G. W., \& Russel, K. E. (1947). Friedel-Crafts catalysts in polymerization: Kinetic measurements and the role of water. Nature (London, United Kingdom), 160(4068), 543. 
91. Norrish, R.G.W. Graft Copolymer, 1957, GB788175,19571223.

92. de Mayo, P., \& Takeshita, H. (1962). Sattar, ABMA (p. 119). London: Proceedings of Chemical Society.

93. Matinez-Haya, R., \& Mazo, L. (2018). König, Reinventing the de Mayo reaction: Synthesis of 1,5- diketones or 1,5-ketoesters via visible light $[2+2]$ cycloaddition of $\beta$-diketones or $\beta$-ketoesters with styrenes. Chemical Communications, 54, 11602-11605.

94. Lin, K., Xu, P., Pei, J., \& Lei, L. (2020). Automatic retrosynthetic planning by using template-free models. Chemical Science, 11, 3355-3366.

95. Crimmins, M.T., Rheinhold, T.L. Enone-olefin $2+2$ photocycloaddition. Organic Reactions. 2004.

96. Sarkar, D., Bera, N., \& Ghosh, S. (2020). [2+2] Photocycloaddition in organic chemistry. European Journal of Chemistry, 1 , 1310-1326.

97. Andrew, D., Hastings, D. J., \& Weedon, A. C. (1994). The mechanism of the photochemical cycloaddition reaction between 2-cyclopentenone and polar alkenes: Trapping of triplet 1,4-biradical intermediates with hydrogen selenide. Journal of the American Chemical Society, 116, 10870-10882.

98. Albini, A., \& Fagnoni, M. (2004). Green chemistry and photochemistry were born at the same time. Green Chemistry, 6, 1-6.

99. Protti, S., Dondi, D., Fagnoni, M., \& Albini, A. (2009). Photochemistry as a green synthetic method: Environmental assessment of C-C bond forming reactions. Green Chemistry, 5, 239-249.

100. Meyer, S., Tietze, D., Rau, S., Schäfer, B., \& Kreisel, G. (2007). Photosensitized oxidation of citronellol in microreactors. Journal of Photochemistry and Photobiology, 186, 248-250.

101. Barthelemy, A. L., Dagousset, G., \& Magnier, E. (2016). MetalFree visible-light-mediated hydrotrifluoromethylation of unactivated alkenes and alkynes in continuous flow. Nature Protocols, $11,10-21$.

102. Su, Y., Straathof, N. J. W., Hessel, V., \& Noël, T. (2014). Photochemical transformations accelerated in continuousflow reactors: Basic concepts and applications. Chemistry, 5, 10562-10589.

103. Gorges, R., Meyer, S., \& Kreisel, G. (2004). Photocatalysis in microreactors. Journal of Photochemistry, 167, 95-99.

104. Tung, C. H., Wu, L. Z., Zhang, L. P., \& Chen, B. (2003). Supramolecular systems as microreactors: Control of product selectivity in organic phototransformation. Accounts of Chemical Research, 36, 39-47.

105. Lu, H., Schmidt, M. A., \& Jensen, K. F. (2001). Photochemical reactions and on-line UV detection in microfabricated reactors. Lab on a Chip, 1, 22-28.

106. Coyle, E. E., \& Oelgemöller, M. (2008). Micro-photochemistry: Photochemistry in microstructured reactors: The new photochemistry of the future? Photochemical \& Photobiological Sciences, 7, 1313-1322.
107. Protti, S., Ravelli, D., Fagnoni, M., \& Albini, A. (2009). Solar light-driven photocatalyzed alkylations: Chemistry on the window ledge. Chemical Commununication, 7, 7351-7735.

108. Ravelli, D., Dondi, D., \& Fagnoni, A. (2009). Photocatalysis: A multi-faceted concept for green chemistry. Chemical Society Review, 38, 1999-2011.

109. Ravellli, D., \& Protti, S. (2016). Decatungstate anion for photocatalyzed "window ledge" reactions. Accounts Chemical Research, 49, 2232-2242.

110. Silva, P. E., Jr., Amin, H. I. M., Nauth, A. M., Protti, S., \& Opatz, T. (2018). Flow Photochemistry of azosulfones: Application of "Sunflow" reactors. ChemPhotoChem, 2, 878-883.

111. Su, Y., Straathof, N. J. W., Hessel, V., \& Noël, T. (2014). Photochemical transformations accelerated in continuous-flow reactors: Basic concepts and applications. Chemical European Journal, 20, 10562-10589.

112. Garlets, Z. J., Nguyen, J. D., \& Stephenson, C. R. J. (2014). The development of visible light photoredox catalysis in flow. Israel Journal of Chemistry, 54, 351-360.

113. Straathof, N. J. W., Straathof, H. P. L., Gemoets, X., Wang, J. C., Schouten, V., \& Hessel, N. T. A. (2009). Rapid trifluoromethylation and perfluoroalkylation of five-membered heterocycles by photoredox catalysis in continuous flow. Chemsuschem, 7 , $1612-1617$.

114. Straathof, N. J. W., Tegelbeckers, B. J. P., Hessel, V., Wang, X., \& Noël, T. A. (2014). Mild and fast photocatalytic trifluoromethylation of thiols in batch and continuous flow. Chemical Science, 5, 4768-4773.

115. Maskill, K. G., Knowles, J. P., Elliott, L. D., \& Alder, R. W. (2013). Complexity from simplicity: tricyclic aziridines from the rearrangement of pyrroles by batch and flow photochemistry. Angewandte Chemie International Edition, 52, 1499-1502.

116. Coyle, E. E., \& Oelgemöller, M. (2008). Micro-photochemistry: Photochemistry in microstructured reactors. The new photochemistry of the future? Photochemical \& Photobiological Sciences, 7, 1313-1322.

117. Protti, S., Ravelli, D., Fagnoni, M., \& Albini, A. (2009). Solar light-driven photocatalyzed alkylations: Chemistry on the window ledge. Chemical Communications, 7, 7351-7353.

118. Ravelli, D., Dondi, D., \& Fagnoni, A. A. (2009). Photocatalysis. A multi-faceted concept for green chemistry. Chemical Society Review, 38, 1999-2011.

119. Ravelli, D., Protti, S., Fagnoni, M., Silva, P. E., Jr., Amin, H. I. M., Nauth, A. M., et al. (2018). Photorganic catalysts, flow photochemistry of azosulfones: Application of "sunflow" reactors. ChemPhotoChem, 2, 878-883.

120. Ravelli, D., Protti, S., \& Fagnoni, M. (2016). Decatungstate anion for photocatalyzed "window ledge" reactions. Accounts of Chemical Research, 49, 2232-2242. 